\title{
Contrasting chlorophyll- $a$ seasonal patterns between nearshore and offshore waters in the Bohai and Yellow Seas, China: A new analysis using improved satellite data
}

\author{
Yueqi Wang ${ }^{\text {a,b,c,*, Zhiqiang Gao }}{ }^{\text {a,b }}$ \\ ${ }^{\text {a }}$ Key Laboratory of Coastal Zone Environmental Processes and Ecological Remediation, Yantai Institute of Coastal Zone Research, Chinese Academy of Sciences, 264003, \\ Yantai, Shandong, PR China \\ ${ }^{\mathrm{b}}$ Shandong Key Laboratory of Coastal Environmental Processes, Yantai Institute of Coastal Zone Research, Chinese Academy of Sciences, 264003, Yantai, Shandong, PR \\ China \\ ${ }^{\mathrm{c}}$ Center for Ocean Mega-Science, Chinese Academy of Sciences, Qingdao, 266071, PR China
}

\section{A R T I C L E I N F O}

\section{Keywords:}

Chl- $a$ seasonal cycle

Remote sensing

Bohai and yellow seas

Cluster analysis

Principal environmental drivers

\begin{abstract}
A B S T R A C T
The seasonal cycles of sea surface Chlorophyll- $a$ (Chl-a) concentration in the Bohai and Yellow Seas (BYS) were examined using new remotely sensed Chl- $a$ products derived using a regional algorithm. Based on objective clustering analysis, two contrasting Chl- $a$ seasonal patterns were delineated: 1) A nearshore pattern with a longlasting Chl- $a$ peak from spring to autumn, coinciding with sufficient nutrient supply and high light availability, and lower Chl- $a$ values in winter due to the light-limitation as a consequence of low solar irradiance and high diffuse attenuation coefficient of light for the water column; 2) An offshore pattern with a strong spring bloom triggered by alleviated light limitation and abundant nutrients coinciding with high water column stability. A weak autumn peak induced by new nutrient replenishment from bottom re-suspension and horizontal transportation, a low Chl- $a$ trough in winter mainly attributed to light-limitation, and a Chl- $a$ trough in summer due to nutrient scarcity were observed. The linkages between the province-specific Chl- $a$ seasonal patterns and the seasonal cycles of the corresponding environmental variables as well as other potential influencing factors are comprehensively delineated and discussed.
\end{abstract}

\section{Introduction}

Seasonal pulses of phytoplankton growth set the rhythm of marine ecosystems (Barnes and Hughes, 1999; González Taboada and Anadón, 2014) and represent an important influx of atmospheric $\mathrm{CO}_{2}$ into the oceans (Falkowski et al., 1998). Seasonal cycles of phytoplankton biomass commonly exhibit different patterns over different regions of the ocean because the processes affecting their growth and demise, such as water temperature, incident solar irradiance, water column stability, nutrient supply, and grazing pressure, vary with the oceanographic conditions (Sapiano et al., 2012; Yoder et al., 1993). Consequently, documenting the seasonal cycles of phytoplankton biomass is a fundamental task and helps to detect and quantitatively evaluate the response of the marine ecosystem to environmental changes and its ability to uptake the atmospheric $\mathrm{CO}_{2}$ (Platt and Sathyendranath, 2008). Knowledge of the seasonal cycles of phytoplankton biomass and their underlying mechanisms are necessary for further exploring the interannual variations, decadal trends as well as phenology changes in phytoplankton biomass.

As the main pigment of phytoplankton, chlorophyll- $a$ (Chl- $a$ ) is considered as an appropriate index or proxy of phytoplankton biomass in the ocean (Richards and Thompson, 1952; Ryther and Yentsch, 1957) and its variability represents changes in the phytoplankton biomass. Seasonal patterns of Chl- $a$ have been evaluated widely using time series of in situ surveys (Carstensen et al., 2007; Garcia et al., 2008; Gong et al., 2003) or satellite remote sensing retrievals (Friedland et al., 2018; McClain, 2009; Yoder et al., 2002). In situ survey provides a way for studing the detailed features but has obvious coverage constraints, whereas satellite remote sensing is able to detect Chl- $a$ variability on large scales, but with inevitably accuracy problems, especially over complex coastal waters (Melin et al., 2007; Odermatt et al., 2012).

The Bohai and Yellow Seas (BYS), located in northern China, are

\footnotetext{
* Corresponding author. Yantai Institute of Coastal Zone Research, CAS, 17th Chunhui Road, Laishan District, 264003, Yantai, China.

E-mail address: yueqiwang@yic.ac.cn (Y. Wang).
} 
connected by the Bohai Strait (Fig. 1). The BYS are mostly underlain by a shallow continental shelf (water depth $<100 \mathrm{~m}$ ). Numerous rivers from the surrounding continents, including two of the largest rivers in the world (Yangtze River and Yellow River), flow into the BYS (Fig. 1), supplying large amounts of fresh water and sediments, and also providing substantial land-sourced nutrients that support phytoplankton growth. The East Asian monsoon associated with seasonal changes in atmosphere temperature dominate the meteorological conditions of the BYS (Wei et al., 2010a; Wu et al., 2016; Zheng et al., 2017), imposing strong impacts on the physical environments of these seas, such as the water column stratification (Park et al., 2015; Tan and Shi, 2012), the front structure (Chen, 2009; Lie et al., 2009) and the current system (Mask et al., 1998; Yanagi and Takahashi, 1993) therein. These seasonal physical processes regulate the phytoplankton standing stock in the euphotic layer through influencing light availability, nutrient supply and grazing pressure, thereby impacting the seasonal cycles of Chl- $a$ (Liu and Wang, 2013).

The seasonal patterns of Chl- $a$ in the BYS have been studied based on various field surveys (Wei et al., 2004; Zhang et al., 2009a; Zhou et al., 2013). However, the lack of spatial coverage hindered the outcomes from field surveys. Firstly, it is difficult to get comprehensive images of seasonal distributions of Chl- $a$ because of the low spatial coverage and dispersed samples from the field surveys. Secondly, even within one cruise, the sampling times at the locations are not always strictly synchronous. Particularly for large spatial domains, the survey could last for one to several months, which is too long for accurately documenting the periodic short-duration events. For example, the high Chl- $a$ values induced by algae blooms (e.g. spring phytoplankton bloom, red tide and green tide) usually last only for two or three weeks in specific locations (Hu et al., 2010; Liu et al., 2013, 2015b; Song et al., 2016). Therefore, the constructed Chl- $a$ seasonal series from a long-lasting survey might miss some transient but important features. Thirdly, when the field surveys are carried out only for a few years, the constructed seasonal series might not be able to represent the periodic climatology. For example, when extremely low-frequency bloom events (e.g. induced by typhoon) occur during or around the period of the field surveys, the constructed Chl- $a$ seasonal patterns could deviate from their actual seasonal climatology (Li et al., 2013b; Son et al., 2006; Zheng and Tang, 2007).

In the last decade, satellite remote sensing has been widely used for investigating Chl- $a$ dynamics in the BYS because of the relatively low cost, large spatial coverage, and high temporal frequency (Liu and Wang, 2013; Yamaguchi et al., 2012; Zhang et al., 2017). However, the inherent defects in the ocean color remote sensing technology, such as missing values due to cloud coverage and biased values due to inaccurate algorithms over optically complex coastal waters, could inevitably reduce the reliability of the results (Melin et al., 2007; Odermatt et al., 2012). At present, the standard Chl- $a$ algorithm is still the primary choice for analyzing Chl- $a$ dynamics in the BYS because of its easy access as well as the convenience for comparisons of the results with previous studies (Fu et al., 2016; Liu and Wang, 2013; Yamaguchi et al., 2012). However, in order to acquire reliable Chl- $a$ dynamics from the standard Chl- $a$ products, some compromises had to be made for their applications in the BYS. For instance, only the relative patterns were considered in some studies (Fu et al., 2016; Liu and Wang, 2013), and some other studies paid attention only to the Chl- $a$ variations in summer and/or

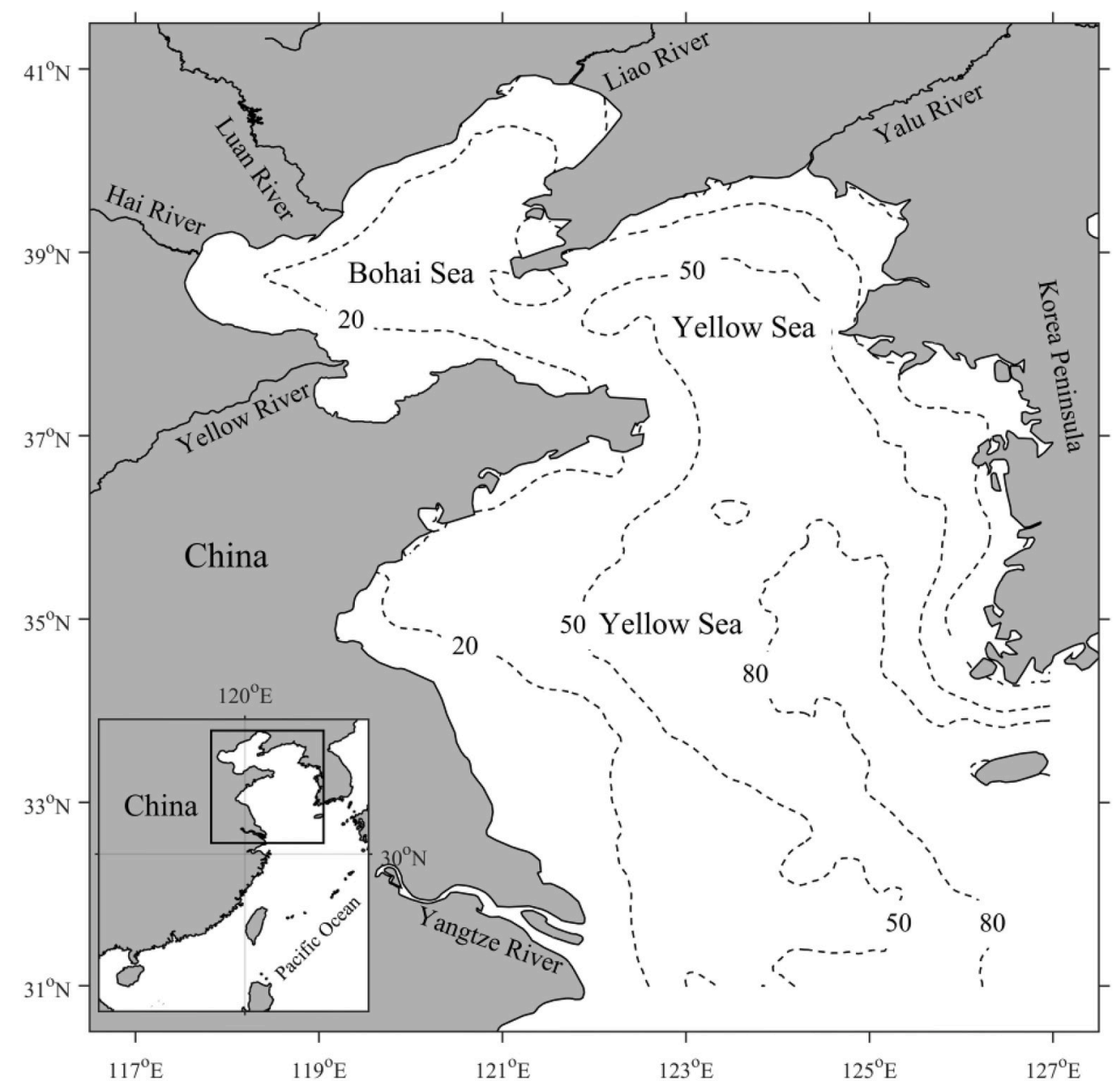

Fig. 1. Bathymetric and geographic map of the study area. 
spring seasons when the standard satellite Chl- $a$ has a relatively high accuracy (Yamaguchi et al., 2012, 2013).

To promote confidence of satellite Chl- $a$ products, we developed a regional statistical Chl- $a$ algorithm based on the generalized additive model (GAM), which has high accuracy as reported by our previous study (Wang et al., 2017). The reasons for improvement are discussed in Wang et al. (2017), and they primarily relate to the increased number of optical bands in the model. It also considered some geographical features, which might eliminate some of the biases originating from the improper atmospheric correction and accommodated the effect of suspended sediments on Chl- $a$ estimation in turbid coastal waters. In addition, our recent study concluded that not only the magnitudes were overestimated, but also the relatively seasonal patterns were significantly distorted in the standard Chl- $a$ products. In contrast, Chl- $a$ derived from the GAM showed relatively more accurate seasonal features (Wang et al., 2019).

As a typical shelf sea, how does the phytoplankton biomass vary with environmental drivers in a seasonal scale? Which environmental factors drive the Chl- $a$ seasonal patterns? With these questions, we revisited the seasonal cycles of Chl- $a$ in the BYS, based on the accuracy-improved satellite-derived sea surface Chl- $a$ images between July 2002 and December 2016, which were produced by the regional GAM Chl- $a$ algorithm. We proceed in three steps: (1) a weekly satellite Chl- $a$ climatology series was constructed, the missing values were then interpolated to produce a complete climatological weekly Chl- $a$ image series; (2) the most dominant seasonal patterns in the Chl- $a$ climatology were identified using cluster analysis and their spatial distributions were geographically mapped; and (3) several potential environmental parameters were used to address the variables that control or significantly affect the surface Chl- $a$ seasonal cycles in different time scales and over different regions.

\section{Data and methods}

\subsection{Sea surface Chl-a observations}

\subsubsection{In situ sea surface Chl-a measurements}

In situ sea surface Chl- $a$ dataset was used for evaluating the reliability of remotely sensed Chl- $a$ seasonal patterns. These in situ samples were collected from nine cruises conducted during the years 2010-2016 (Fig. 2). These cruises used the same sampling and analysis methods for Chl- $a$ concentration. Three duplicate samples of $1000 \mathrm{ml}$ of sea water were collected using Niskin bottles from a depth of less than $5 \mathrm{~m}$ and then filtered through $47 \mathrm{~mm}$ Whatman GF/F filters under low vacuum. The filters were kept in the dark at $-20^{\circ} \mathrm{C}$ before laboratory analysis. In the laboratory, photosynthetic pigments were extracted with $15 \mathrm{ml}$ of
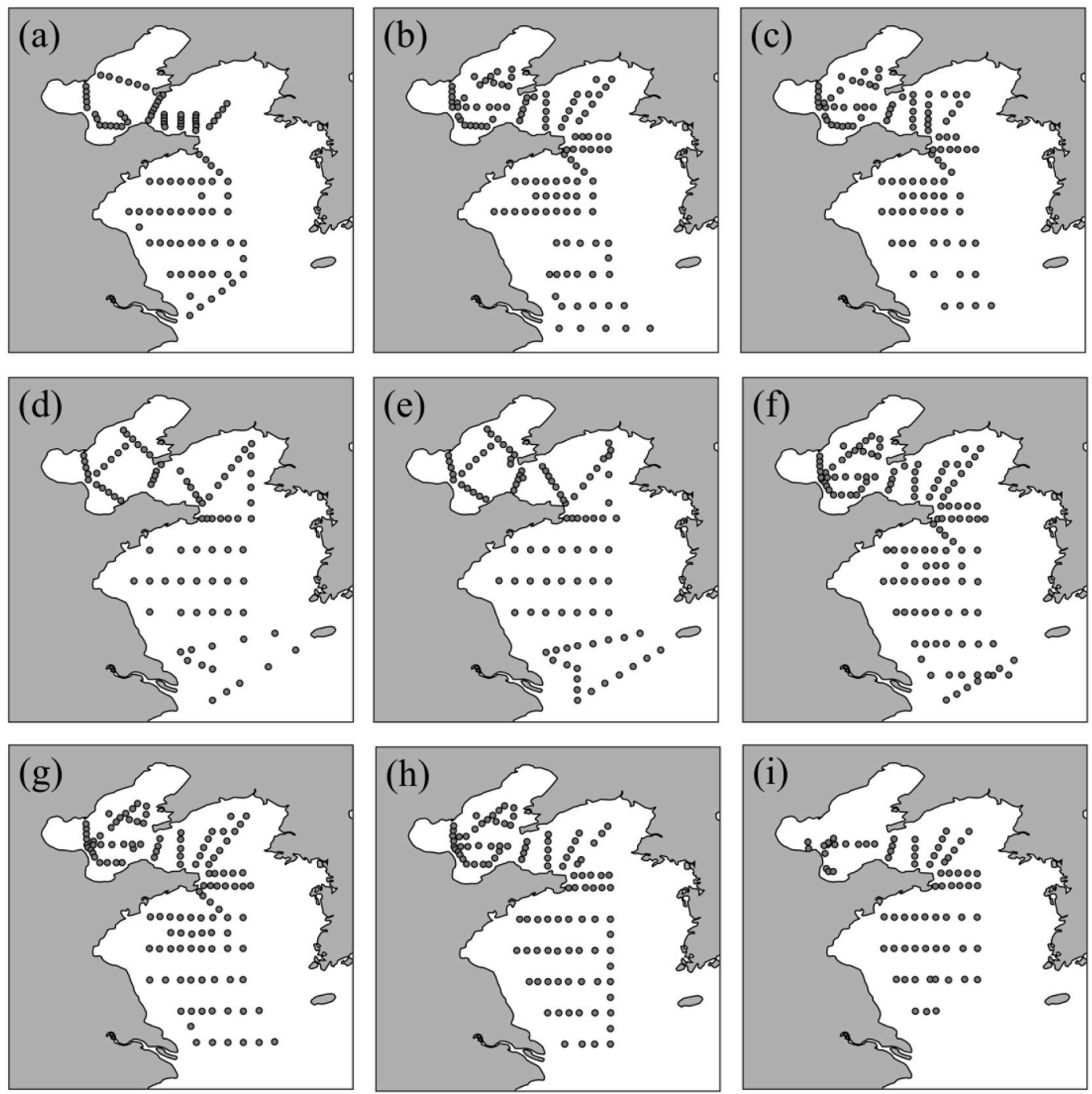

Fig. 2. The sites of the in situ Chl-a samples for each cruise. (a) 20 April-04 May 2010; (b) 02 May-20 May 2012; (c) 02 November-19 November 2012 ; (d) 22 June-09 July 2013; (e) 06 November-24 November 2013; (f) 28 April-18 May 2014; (g) 07 November-23 November 2014; (h) 17 August-05 September 2015 ; (i) 15 January30 January 2016. 
$90 \%$ acetone in the dark for $24 \mathrm{~h}$ at $4{ }^{\circ} \mathrm{C}$ (Lorenzen, 1967) and the Chl- $a$ concentration was determined spectrophotometrically (TU-1800, Persee, China).

\subsubsection{Remotely sensed sea surface Chl-a}

The global standard OC3M algorithm (ocean Chl- $a$ three-band algorithm for MODIS) (O'Reilly et al., 2000) and the regional GAM algorithm (statistical Generalized Additive Model) (Wang et al., 2017) were used to calculate daily sea surface Chl- $a$ concentrtions based on the MODIS remote sensing reflectance $\left(R_{\mathrm{rs}}\right)$ datasets. The weekly Chl- $a$ images were composited as median of the inclusive daily Chl- $a$ datasets. Then, the weekly climatology images with 52 time steps were constructed by the median of the corresponding weekly images over 15 years (2003-2016). The missing data in the climatological weekly images were filled using the Data Interpolation Empirical Orthogonal Function (DINEOF) method (Alvera-Azcárate et al., 2007; Beckers et al., 2006; Wang and Liu, 2014), which is a self-consistent, parameter-free technique for gappy data reconstruction and with high computational speed. Finally, a complete climatological weekly Chl- $a$ dataset with 52 time series and 30544 spatial pixels were constructed for further analysis.

\subsection{Sea surface nutrients datasets}

In situ nutrients were measured over the first five cruises of the field surveys as shown in Fig. 2a-e. The nutrients included dissolved inorganic nitrogen (DIN), dissolved inorganic phosphorus (DIP) and dissolved silica (DSi), and were analyzed using Flow Injection Analysis (AA3, Bran + Luebbe, Germany) after filtration through cellulose acetate membranes (Whatman, $0.45 \mu \mathrm{m}$ ). Nutrient analyses were executed according to the World Ocean Circulation Experiment (WOCE) Methods Manual WHPO 91-1 (Gordon et al., 1993; Knap et al., 1996).

The nutrient observations from historical literatures (Chen, 2008, 2009; Fu et al., 2009; Leng, 2016; Li et al., 2013a; Wang, 2003; Wang et al., 2003; Wei et al., 2010b, 2016; Zhang et al., 2009b) were also extracted and summarized in seasonal scales. Both the in situ measurements and the nutrient values reported in the literature were averaged for the nearshore and offshore provinces to produce a complete seasonal succession of the sea surface nutrient condition. Finally, both the concentration and structure of nutrients for each province were achieved and analyzed.

\subsection{Satellite remote sensing reflectance}

Daily remote sensing reflectance $\left(R_{\mathrm{rs}}\right)$ images at visible wavelength range (central band of $412,443,469,488,531,547,555,645,667$, and $678 \mathrm{~nm}$ ) from the MODIS/Aqua level 2 Global Area Coverage (GLA) for the period of July 4, 2002 to December 31, 2016 over the geographical area of $31-41^{\circ} \mathrm{N}$ and $117-127^{\circ} \mathrm{E}$ were downloaded from the website of Goddard Space Flight Center OceanColor (http://oceancolor.gsfc.nasa. gov/) at $1 \mathrm{~km} \times 1 \mathrm{~km}$ spatial resolution. The daily $R_{\mathrm{rs}}$ images were remapped onto a common $1 / 24^{\circ} \times 1 / 24^{\circ}$ grid to reduce the data volume.

\subsection{Environmental data}

\subsubsection{Sea surface temperature}

The satellite sea surface temperature (SST) data used in this study is the National Oceanic and Atmospheric Administration (NOAA) Optimum Interpolation (OI) $1 / 4^{\circ}$ Daily SST (also known as Reynolds 0.25 v.2) (Reynolds and Smith, 1994; Reynolds et al., 2007), obtained from the National Climatic Data Center, NOAA (https://www.ncei.noaa. gov/data/). Daily SSTs for the period from July 4, 2002 to December 31,2016 were used to composite the climatological weekly SST images.

\subsubsection{Sea surface wind}

The daily satellite sea surface wind (SSW) data from July 4, 2002 to December 31,2016 at a spatial resolution of $1 / 4^{\circ} \times 1 / 4^{\circ}$ were acquired from the product of Cross-Calibrated, Multi-Platform (CCMP) (version 2.0 and level 3.5). This product was derived through cross calibration and assimilation of ocean surface wind data from the SSM/I, TMI, AMSR-E, SeaWinds on the QuikSCAT, and SeaWinds on the ADEOS-II (Atlas et al., 1996, 2011) provided by the NASA Physical Oceanography Distributed Active Archive Center (PO.DAAC) (http://podaac.jpl. nasa.gov/). In this study, the climatological weekly images for the zonal and meridional components of wind as well as the wind speed were composited from the daily wind data.

\subsubsection{Total suspended matter}

The daily images of the total suspended matter (TSM) concentration in the BYS were calculated from the daily MODIS $R_{\mathrm{rs}}$ data using an empirical algorithm developed by Zhang et al. (2010). The climatological weekly TSM images were composited from the daily images with the spatial resolution of $1 / 24^{\circ} \times 1 / 24^{\circ}$.

\subsubsection{Photosynthetically available radiation}

The daily satellite derived photosynthetically available radiation (PAR) data from the MODIS/Aqua was acquired from Goddard Space Flight Center OceanColor website (http://oceancolor.gsfc.nasa.gov/) at $1 \mathrm{~km} \times 1 \mathrm{~km}$ spatial resolution for the time span from July 4, 2002 to December 31, 2016. The PAR datasets were produced using the algorithm developed by Frouin (2003). The climatological weekly images were composited from the daily PAR dataset, and the grid was resampled to $1 / 24^{\circ} \times 1 / 24^{\circ}$.

\subsubsection{Diffuse attenuation coefficient of PAR}

The attenuation coefficient of instantaneous PAR for the upper water column was calculated from the MODIS $R_{\mathrm{rs}}$ data using the algorithm constructed in Son and Wang (2015). Then the diffuse attenuation coefficient of the daily PAR $\left(K_{\mathrm{par}}\right)$ were derived from the attenuation coefficient of instantaneous PAR using a simple analytical form described in Wei and Lee (2013). The climatological weekly $K_{\text {par }}$ images were composited from the daily images, and the grid was resampled to $1 / 24^{\circ}$ $\times 1 / 24^{\circ}$.

\subsubsection{Mixed layer depth}

The monthly mixed layer depth (MLD) images from July 2002 to December 2016 at a spatial resolution of $1 / 24^{\circ} \times 1 / 24^{\circ}$ were obtained from the website of Ocean productivity group of the Oregon State University (http://www.science.oregonstate.edu/ocean.productivity/i ndex.php). The MLD was retrieved from the Hybrid Coordinate Ocean Model (HYCOM) (Chassignet et al., 2007; Halliwell, 2004). The climatological monthly images were composited from the monthly MLD images and the climatological weekly MLD images were then generated from the climatological monthly images by temporal interpolation.

\subsubsection{Mean PAR intensity in mixed layer}

The mean PAR intensity in the mixed layer $\left(I_{\mathrm{m}}\right)$ was calculated as PAR $\times \frac{1-e^{-K_{\mathrm{par}} \times M L D}}{K_{\mathrm{par}} \times M L D}$, according to Kirk (1994), where PAR represents the sea surface PAR intensity, $K_{\mathrm{par}}$ is the diffuse attenuation coefficient of PAR, and MLD represents the mixed layer depth.

\subsection{DINEOF reconstruction}

The cluster analysis generally requires complete time series of input maps with no data voids. Therefore, the missing values in climatological weekly satellite Chl- $a$ data set were reconstructed using the Data Interpolation Empirical Orthogonal Function (DINEOF) method (Alvera-Azcárate et al., 2007; Beckers et al., 2006; Wang and Liu, 2014). This approach is a self-consistent, parameter-free technique for gappy 
data reconstruction with high computational speed. It require no priori information and can be used in different types of observations (e.g., SST and Chl-a) to perform multivariate reconstruction (Wang and Liu, 2014; Zhao and He, 2012). For a more detailed description of the DINEOF algorithm, refer to Beckers and Rixen (2003), Alvera-Azcárate et al. (2005) and Wang and Liu (2014). As a result of DINEOF reconstruction, a cloud-free climatological weekly Chl- $a$ dataset with 30544 spatial pixels and 52 temporal images was constructed.

\section{6. $k$-means cluster analysis}

Multivariate clustering was used to examine the dominant Chl-a seasonal cycles of the BYS, and then the pixels with similar seasonal patterns were identified and grouped within the study area. Specifically, a k-means multivariate cluster analysis (Kanungo et al., 2002) was performed on the de-trended (temporal means removed) and normalized (temporal standard deviation divided) climatological weekly Chl- $a$ data set, in order to group the locations into the assigned number of groups according to their seasonal shapes, with the squared Euclidean distance as the metric of similarity and randomly selected cluster centroids as starting points (Foukal and Thomas, 2014; McGinty et al., 2016). As a result, the pixels have similar cycles were grouped. The center (average cycle) within each group is then computed to provide a single characteristic seasonal cycle that is statistically representative of the group as a whole. Geographic maps of these groups reveal ocean areas that host a single regime or closely similar regimes. Similar techniques have been already used to cluster pixels having similar patterns of the considered parameters (Foukal and Thomas, 2014; Gabriel et al., 2013; Krug et al., 2017; Shalin et al., 2018).

The k-means algorithm requires specification of $k$, the number of clusters to produce (Kanungo et al., 2002), which we identify in the climatology. The appropriate number of clusters is inherently subjective (Foukal and Thomas, 2014; Manly and Alberto, 2016; Pielou, 1984), though there are statistical tests that can guide the user. One commonly used tool in k-means is silhouette analysis (Rousseeuw, 1987), which calculates for each pixel the normalized difference between the distance to the centroid of its assigned cluster and the distance to the next closest cluster centroid to which it was not assigned. Thus the average silhouette value can provide an indication of the optimal number of clusters within a dataset.

\section{Results}

\subsection{Partition of the BYS based on Chl-a seasonal patterns}

Cluster analysis of the weekly climatological Chl- $a$ data suggests that the BYS could be partitioned into two contrasting provinces based on the Chl- $a$ seasonal cycles (Fig. 3) and the two regions are approximately
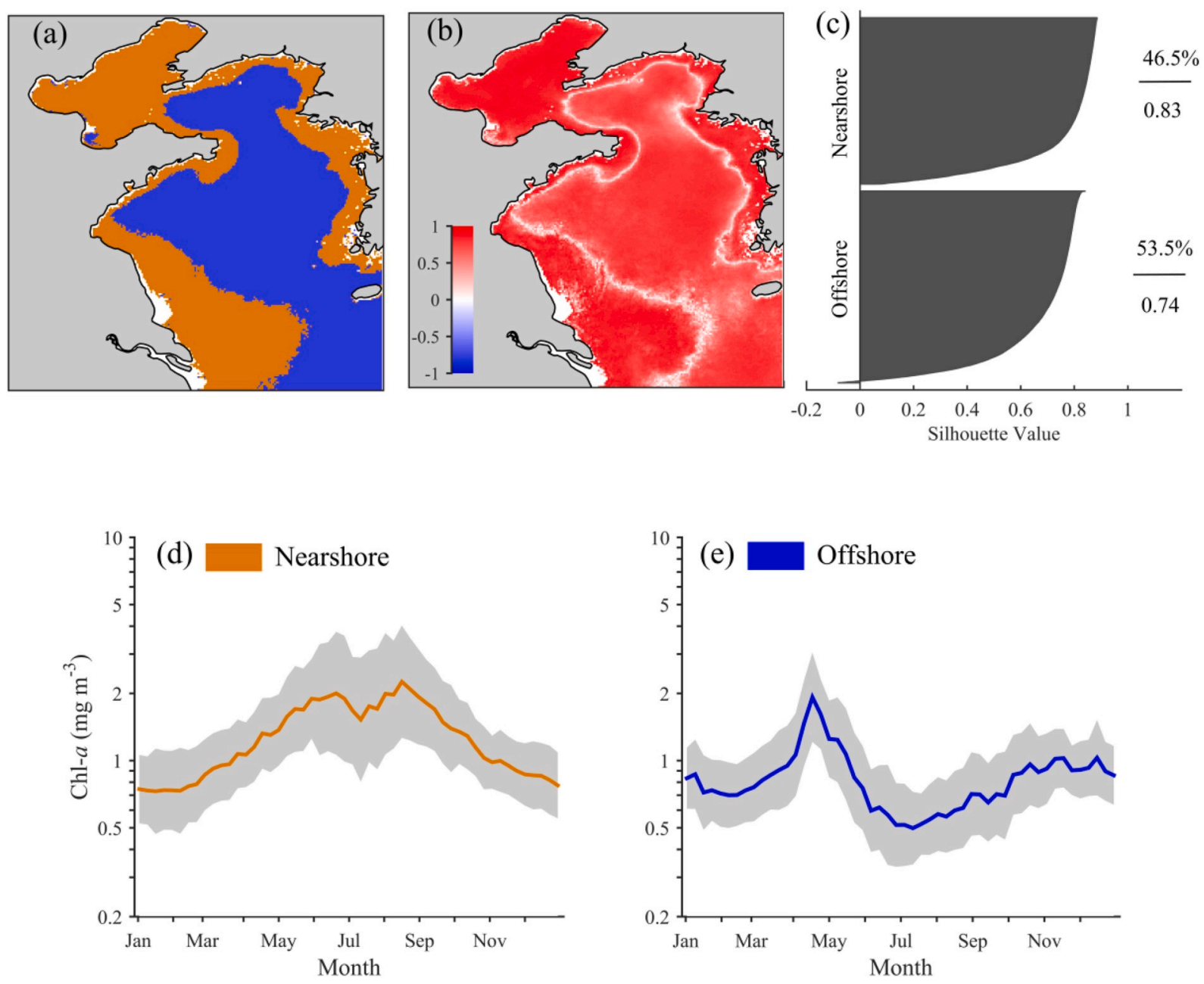

Fig. 3. The result of Chl- $a$ seasonal cycles clustering. (a) Spatial geography of the two cluster provinces in the BYS. (b) Silhouette values across the study area indicate similarity to their respective cluster centroid. (c) Estimated silhouette values for each cluster. The percentage of occupied area (above) and average silhouette value (below) for each cluster are displayed in the right margin. (d) and (e) show the average seasonal patterns of Chl- $a$ (straight line) and the corresponding standard errors (gray shade) within the two provinces. (For interpretation of the references to color in this figure legend, the reader is referred to the Web version of this article.) 
delimited by the $50 \mathrm{~m}$ isobaths (Figs. 1 and 3a). A distinct winter Chl- $a$ minimum $\left(<0.8 \mathrm{mg} \mathrm{m}^{-3}\right)$ and a long-lasting elevated Chl- $a(>1.5 \mathrm{mg}$ $\mathrm{m}^{-3}$ ) from late spring to early autumn (from May to October) with a minor summertime dip define the nearshore region (brown, $\sim 46.5 \%$ of the study area). Geographically, this seasonal cycle mainly occurs in the nearshore locations with isobaths $<50 \mathrm{~m}$, which include most of the Bohai Sea (Fig. 3a). Hereafter, we refer to this seasonal cycle as "nearshore pattern" and its dominant region is indicated as the "nearshore province". A seasonal Chl- $a$ cycle characterized by a strong spring bloom $\left(\sim 2.0 \mathrm{mg} \mathrm{m}^{-3}\right)$ in April, followed by a long trough $\left(<0.5 \mathrm{mg} \mathrm{m}^{-3}\right)$ period during summer (June to August), and then a weak $\left(\sim 1 \mathrm{mg} \mathrm{m}^{-3}\right)$ autumn bloom (October to November) dominates the offshore region (blue, $\sim 53.5 \%$ of the study area). Geographically, the bimodal annual cycle of Chl- $a$ is mainly present in the central Yellow Sea with isobaths $>50 \mathrm{~m}$ (Figs. 1 and 3a). Hereafter, we refer to this Chl- $a$ seasonal cycle as the "offshore pattern" and its dominant region is indicated as the "offshore province".

The map of silhouette values shows many of the BYS clusters closely to their respective centroids (red regions in Fig. 3b). Almost all of the silhouette values are positive over the BYS with an average of 0.78 (Fig. $3 \mathrm{~b}$ and c). However, some locations in the offshore province near the boundary show low positive or even negative values, often grouping weakly to their centroid (white and blue regions in Fig. 3b), which indicates that assignment errors remain when the iterative k-mean algorithm is stabilized and stopped. Moreover, this phenomenon also implies a transition-like shift rather than a step-like shift between the nearshore and offshore patterns.

\subsection{Seasonal cycles of environmental variables}

To give an intuitive understanding of the seasonal cycles of the environmental variables, the climatologically averaged series of each variable for the nearshore and offshore provinces are presented in Fig. 4 and their spatial distribution for each season is presented in Fig. 5. The seasonal pattern of each variable is synoptically depicted in this section.

\subsubsection{Seasonal cycle of SST}

The climatological series show that the seasonal cycles of SST are similar over both the nearshore and offshore provinces (Fig. 4a). Both of the SST plots show the minima $\left(5-10{ }^{\circ} \mathrm{C}\right)$ in February and the maxima $\left(\sim 25^{\circ} \mathrm{C}\right)$ around August. However, higher SST biases $\left(\sim 5^{\circ} \mathrm{C}\right)$ between the two provinces are found in winter (December to February) than in
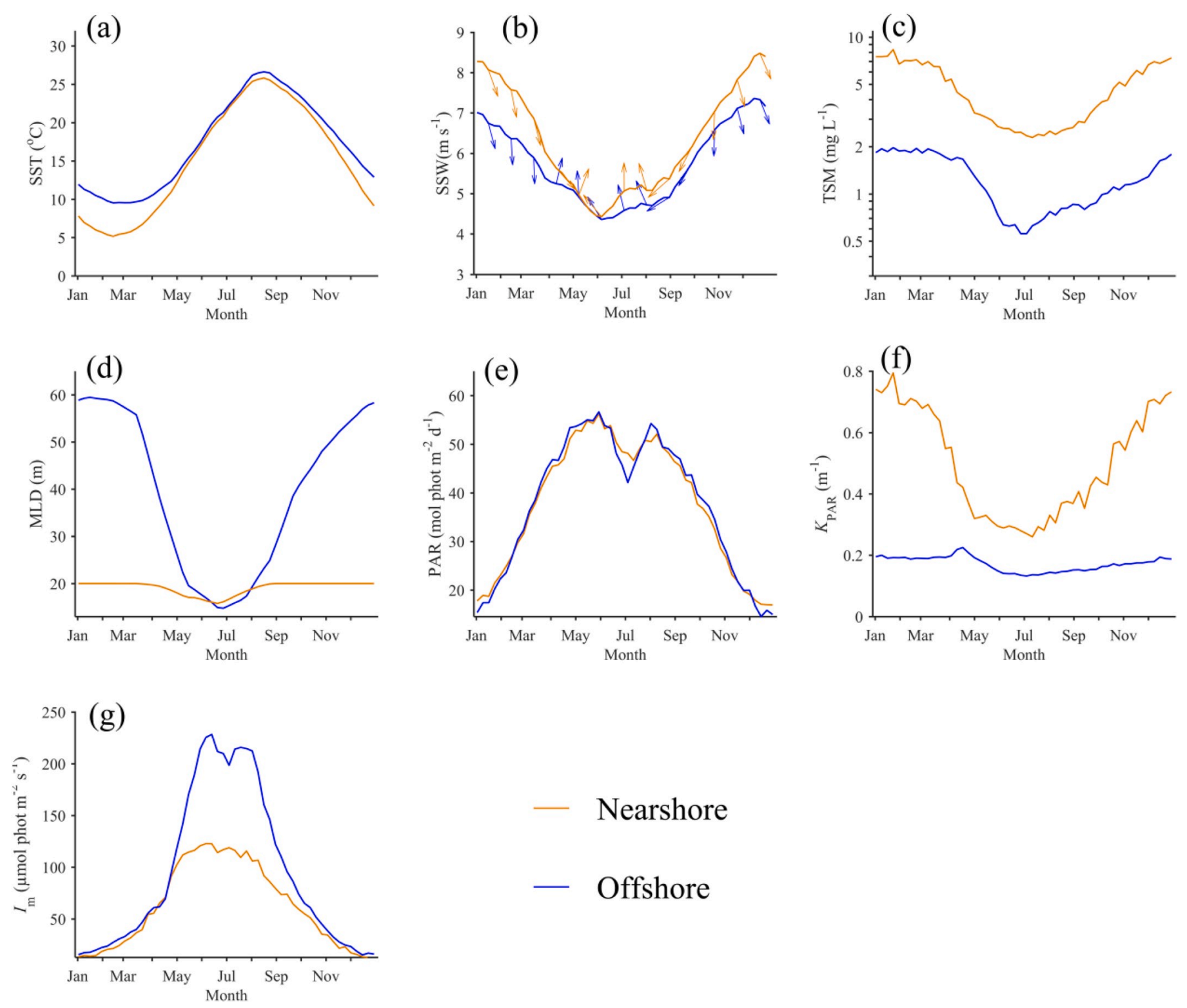

Fig. 4. Seasonal cycles of environmental variables averaged over the two provinces. (a) SST, (b) SSW, (c) TSM, (d) MLD, (e) PAR, (f) $K_{\mathrm{par}}$, and (g) $I_{\mathrm{m}}$. 


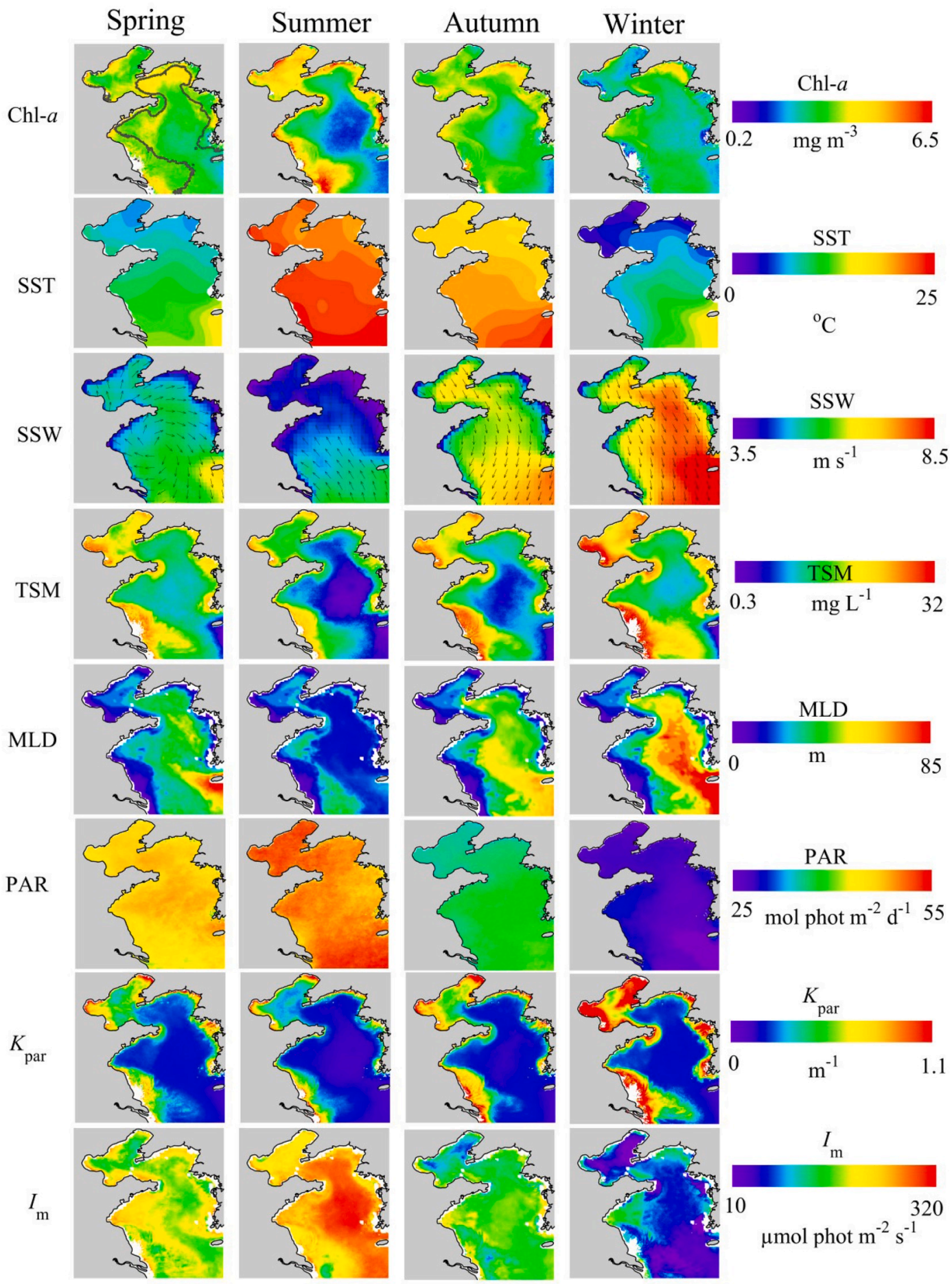

Fig. 5. Spatial distributions of the environmental variables for each season. Spring: March-May; Summer: June-August; Autumn: September-November; and Winter: December-February.

other seasons (Figs. 4a and 5), which is probably due to the strong impact of the Yellow Sea Warm Current (YSWC) over the offshore province in winter (Naimie et al., 2001; Su, 1998).

\subsubsection{Seasonal cycle of SSW}

The climatological series show that the seasonal cycles of SSW exhibit similar patterns both in terms of speed and direction for the two provinces (Figs. 4b and 5). The wind is southerly with a low magnitude $\left(\sim 4 \mathrm{~m} \mathrm{~s}^{-1}\right)$ in summer (June to August) and northerly with a high magnitude $\left(\sim 8 \mathrm{~m} \mathrm{~s}^{-1}\right)$ in winter (December to February), which is consistent with the general patterns of the East Asian monsoon (Su, 1998).

\subsubsection{Seasonal cycle of TSM}

The weekly climatology series of TSM demonstrate significant spatial and seasonal variations (Fig. 4c). The average TSM of the nearshore province is consistently lower than that of the offshore province (Fig. 4c) with a distinct nearshore-offshore gradient (Fig. 5), which is attributed to the higher level of land runoff and the stronger sediment resuspension (Kim et al., 2017; Son et al., 2014; Zhang et al., 2010). On 
the seasonal scale, both of them exhibit lower TSM values $\left(2-3 \mathrm{mg} \mathrm{L}^{-1}\right.$ nearshore and $0.5-0.7 \mathrm{mg} \mathrm{L}^{-1}$ offshore) in summer and higher values (6-8 $\mathrm{mg} \mathrm{L}^{-1}$ nearshore and $1.5-2 \mathrm{mg} \mathrm{L}^{-1}$ offshore) from late autumn to winter (Fig. 4c). In winter, the strong northerly East Asian monsoon induces intensive vertical mixing, thus intensifying the sediment re-suspension, which could increase the TSM in the upper water column. In summer, the weak wind speed reduces the strength of sediment re-suspension, which could decrease the TSM in the upper water column (Zhang et al., 2010; Zhou et al., 2017).

\subsubsection{Seasonal cycle of $M L D$}

The seasonal patterns of MLD show larger biases between the nearshore and offshore provinces. The offshore province has maximum MLD $(\sim 60 \mathrm{~m})$ in winter and minimum MLD $(\sim 15 \mathrm{~m})$ in summer (Figs. $4 \mathrm{~d}$ and 5). The MLD gradually increases during summer to winter and decreases during winter to summer (Fig. 4d). In the nearshore province, the MLD was nearly stationary at an average depth of $20 \mathrm{~m}$ all year-round (Fig. 5), except a little trough $(\sim 15 \mathrm{~m})$ in summer (Fig. 4d). The constant MLD values $(\sim 20 \mathrm{~m})$ from autumn through winter to spring were near to the average water depth $(\sim 21.4 \mathrm{~m})$ of the nearshore province. Considering the variations in SST and SSW, the stationary of MLD demonstrates that the water column might be well mixed from the surface to bottom in the nearshore province all-year round (Lin et al., 2006).

\subsubsection{Seasonal cycles of PAR}

The PAR averages of the two provinces are nearly coherent in the seasonal cycles with higher values $\left(>50\right.$ mol phot $\left.\mathrm{m}^{-2} \mathrm{~d}^{-1}\right)$ in April-October, and lower values $\left(<20\right.$ mol phot $\left.\mathrm{m}^{-2} \mathrm{~d}^{-1}\right)$ were observed during November-March (Fig. 4e), which is mainly related to the intensity of solar irradiance. A short-time dip was observed in July, which could be attributed to the high cloud cover in the summer.

\subsubsection{Seasonal cycle of $K_{\text {par }}$}

The average $K_{\mathrm{par}}$ of the nearshore province is consistently higher than that of the offshore province all-year round (Fig. 4f), which is attributed to the persistently higher levels of total suspended matters along the coast compared with the offshore waters (Figs. 4c and 5) (Kim et al., 2017; Son et al., 2014; Zhang et al., 2010). The nearshore province
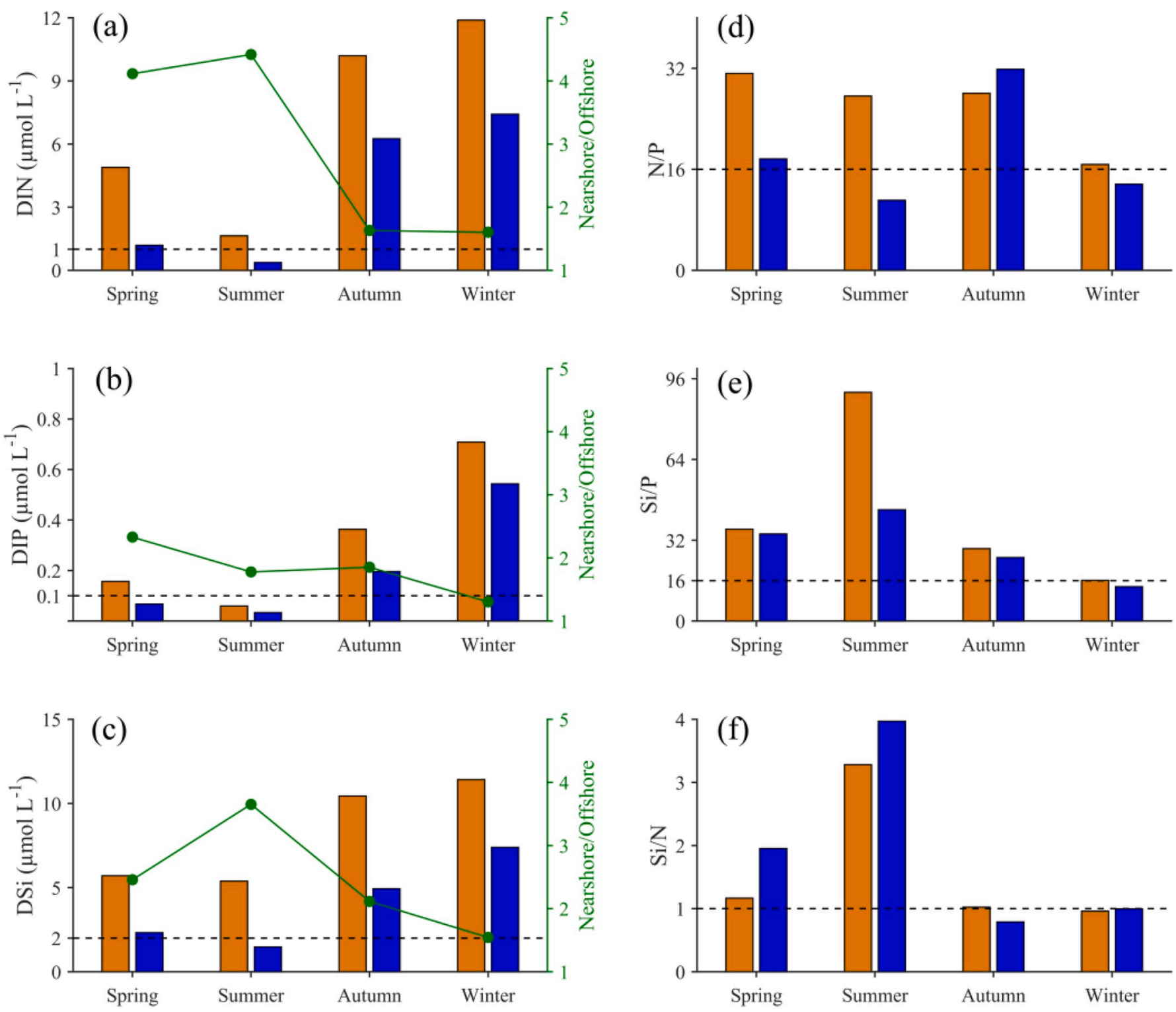

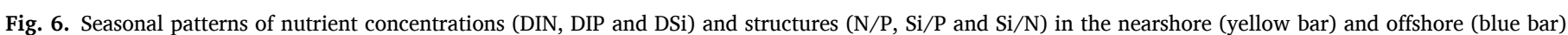

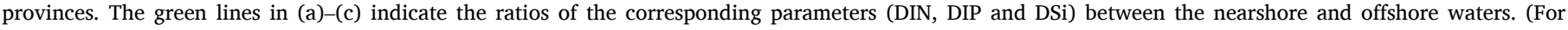
interpretation of the references to color in this figure legend, the reader is referred to the Web version of this article.) 
exhibits significant seasonal variations, with lower values of $K_{\mathrm{par}}(\sim 0.3$ $\left.\mathrm{m}^{-1}\right)$ in summer and higher values $\left(>0.6 \mathrm{~m}^{-1}\right)$ from late autumn to winter, whilst the average $K_{\mathrm{par}}$ for the offshore province was relatively stationary at a low range between 0.1 and $0.2 \mathrm{~m}^{-1}$ (Fig. 4f). In winter, the strong northerly East Asian monsoon induces strong vertical mixing and intensifies the sediment re-suspension, which could increase the TSM and thus increase the $K_{\mathrm{par}}$ in the upper water column (Fig. 4c, f, and Fig. 5). In summer, the weak wind speed reduces the strength of sediment re-suspension, which could decrease the TSM in the water column (Zhang et al., 2010; Zhou et al., 2017), thus increasing the $K_{\text {par }}$ (Fig. 4c, f and 5).

\subsubsection{Seasonal cycle of $I_{m}$}

The $I_{\mathrm{m}}$ of the nearshore and offshore provinces show similar seasonal patterns with higher values in summer due to high PAR (Fig. 4e) coinciding with lower $K_{\text {par }}$ (Fig. 4f), whereas lower values persist from autumn through winter to spring (Fig. 4g) due to low PAR (Fig. 4e) and high $K_{\text {par }}$ (Fig. 4f). The $I_{\mathrm{m}}$ of the offshore province ( $>200 \mu \mathrm{mol} \mathrm{phot} \mathrm{m}^{-2}$ $\left.\mathrm{s}^{-1}\right)$ is evidently higher than that of the nearshore province $(\sim 100 \mu \mathrm{mol}$ phot $\mathrm{m}^{-2} \mathrm{~s}^{-1}$ ) in summer, as a consequence of similar PAR and MLD but quite higher $K_{\mathrm{par}}$ in the nearshore province than in the offshore province (Figs. 4 and 5).

\subsubsection{Seasonal cycle of nutrient concentrations and structures}

The seasonal patterns of sea surface nutrient concentrations (DIN, DIP and DSi) and structures (N/P, Si/P and $\mathrm{Si} / \mathrm{N})$ in the two separated provinces are illustrated in Fig. $6 \mathrm{a}-\mathrm{c}$ and Fig. $6 \mathrm{~d}-\mathrm{e}$. The nutrient concentrations in the two provinces show a similar seasonal pattern with elevated levels from autumn through winter, followed by a decreasing trend from winter to spring before they achieve their lowest levels in summer (Fig. 6a-c). The nutrient levels in the nearshore waters are generally higher than that of the offshore waters all year-round. Ratios of both DIN and DSi between the nearshore and offshore waters exhibit highest values in summer, which demonstrates a strong nutrient spatial gradient in the summer (Fig. 6a-c). For example, the ratios of DIN concentrations between the nearshore and offshore waters in summer and winter are 4.42 and 1.60, respectively. In contrast, the ratios of DIP between the two provinces have a narrow range from 1.3 in winter to 2.3 in spring (Fig. 6b). The nutrient structures show that the N/P values of both the provinces were almost higher than 16 , except for the offshore province in summer and winter (Fig. $6 \mathrm{~d}-\mathrm{f}$ ). The $\mathrm{Si} / \mathrm{P}$ values of both the

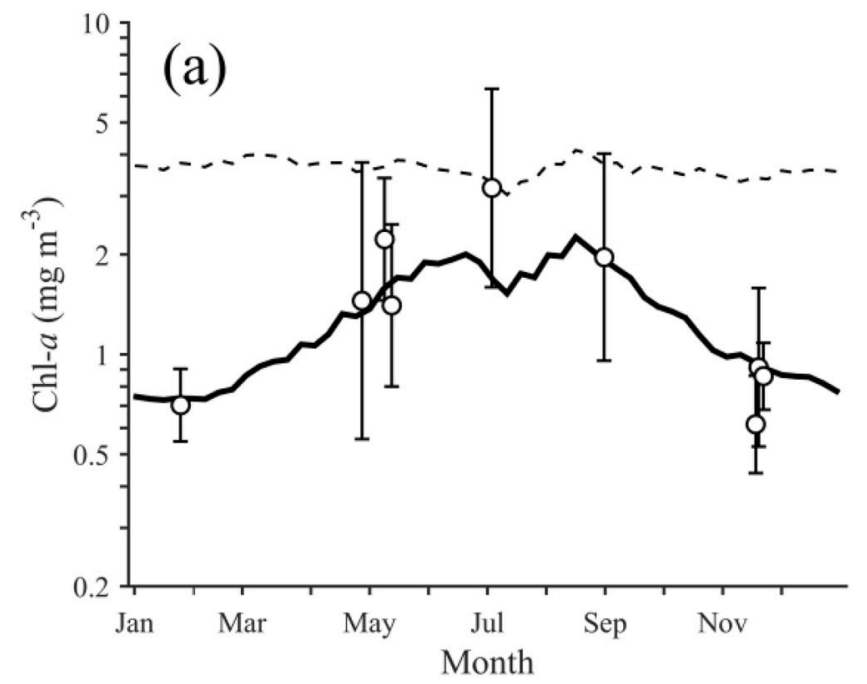

provinces were also higher than 16, except for the offshore province in winter with a value lower than 16 (Fig. 6e). The $\mathrm{Si} / \mathrm{N}$ values were significantly higher than 1 from spring to summer, whereas they were lower than but close to 1 in autumn and winter (Fig. 6f).

\section{Discussion}

\subsection{Reliability of the seasonality derived from GAM Chl-a}

The accuracy of GAM Chl- $a$ algorithm was statistically validated in our previous study, and the GAM prominently outperformed the standard OC3M and semi-analytical Graver-Siegel-Maritorena model version 1 (GSM01) algorithms, in terms of the Chl- $a$ magnitude (Wang et al., 2017). The GAM algorithm significantly alleviates the problem of Chl- $a$ overestimation over the coastal waters. Moreover, our recent study based on extensive in situ Chl- $a$ observations demonstrates that the OC3M algorithm not only produces large errors in Chl- $a$ magnitude but also clearly distorts its seasonality. In comparison, the GAM Chl- $a$ gives more reliable seasonality close to the in situ observations (Wang et al., 2019). Furthermore, as indicated in Fig. 7, the comparisons between seasonal cycles of Chl- $a$ between different sources also confirm that the seasonal cycles of GAM Chl- $a$ (solid line) are closer to the in situ observations (circle with error bar) than the OC3M derived seasonal cycle (dash line). Moreover, besides the GAM algorithm, there are other regional Chl- $a$ algorithms that could be applied in the BYS, such as the Tassan-like algorithm (Hao et al., 2019; Siswanto et al., 2011; Zhang et al., 2017). In comparison, the Chl- $a$ maps produced by the Tassan-like algorithm (Siswanto et al., 2011) and the GAM algorithm have similar spatial and temporal characteristics as both of them alleviate the overestimation of Chl- $a$ values over waters with high sediment suspension. The Chl- $a$ seasonal patterns are in accordance with previous studies using field surveys (Fu et al., 2009; Wang et al., 2012b); the Chl- $a$ in spring, summer, autumn and winter are respectively 1.12, 0.57, 0.65, and 0.65 for the offshore waters, and are respectively 1.0, 2.21, 1.79, and 1.20 for the nearshore waters. In conclusion, to date, the GAM Chl- $a$ is probably the most reliable satellite product that could be used for seasonal analysis of Chl- $a$ in the BYS.

\subsection{Principal mechanisms for Chl-a seasonal cycles}

Two contrasting Chl- $a$ seasonal patterns were observed in the BYS,

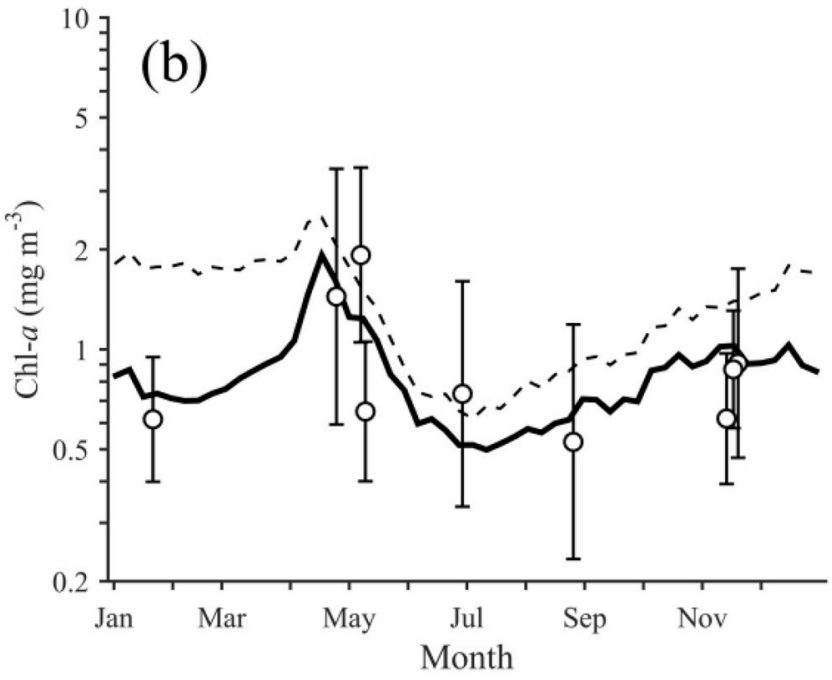

Fig. 7. Time series comparisons of satellite Chl- $a$ concentrations derived from the GAM and OC3M algorithms with respect to in situ Chl- $a$ observations for the (a) nearshore and (b) offshore provinces. 
based on the shapes of the climatological annual series: a unimodal "nearshore pattern" that has one long-lasting spring to autumn peak distributes over the nearshore waters, while a bimodal "offshore pattern" that has a prominent maxima in spring and a weak peak in autumn dominates the offshore region. In this section, we will explore how the related environmental variables (e.g. SST, SSW, light, and nutrients) and other potential factors (e.g. nutrient structure, horizontal transport, and atmospheric input) impact the two distinct seasonal patterns of Chl- $a$. The seasonal variability in Chl- $a$ and its association with the light and nutrient conditions are shown in Fig. 8. All the data series in Fig. 8 were normalized to unitless values and are smoothed by the spline method. The principal processes responsible for the differences in seasonal cycles of Chl- $a$ in the nearshore and offshore regions are delineated in Fig. 9.

\subsubsection{Nearshore pattern}

In winter, low Chl- $a$ value coincides with low light intensity and high nutrient concentration in the nearshore waters demonstrates that the phytoplankton growth was mainly limited by the scarcity of light during this period (Fig. 8). The strong wind (Fig. 4b) drives strong vertical mixing in the water column (Fig. 4d), thereby enhancing the bottom sediment re-suspension. The strong sediment re-suspension contributes to higher levels of TSM (Fig. 4c) (Qian et al., 2002; Shang et al., 2016) and enhances nutrient supply from the bottom up to the water column (Fu et al., 2009; Wang et al., 2012a). Despite the low terrestrial-oriented nutrient supply due to decreased precipitation and low river run-off (Qian et al., 2002; Tong et al., 2015), the high nutrient level persists during winter, which is attributed to adequate supply from the bottom sediment re-suspensions (Figs. $8 \mathrm{c}$ and 9d). In addition, the low solar irradiance on the surface combined with the high light diffuse attenuation coefficient of the water column certainly result in low level of light availability in the water column (Figs. $8 c$ and 9d). Therefore, the phytoplankton growth in the nearshore waters is controlled by the strong light limitation in winter.

After winter, a prominent long-lasting spring-autumn Chl- $a$ peak coincides with the elevated light intensity and slightly diminished nutrient concentration dominates the nearshore province (Fig. 8). From spring to summer, the decreasing wind speed leads to the gradual weakening of vertical mixing, thus resulting in a decreased bottom sediment re-suspension (Bian et al., 2013; Shang et al., 2016). The light availability is significantly enhanced in the water column due to increased solar irradiance and decreased diffuse attenuation coefficient
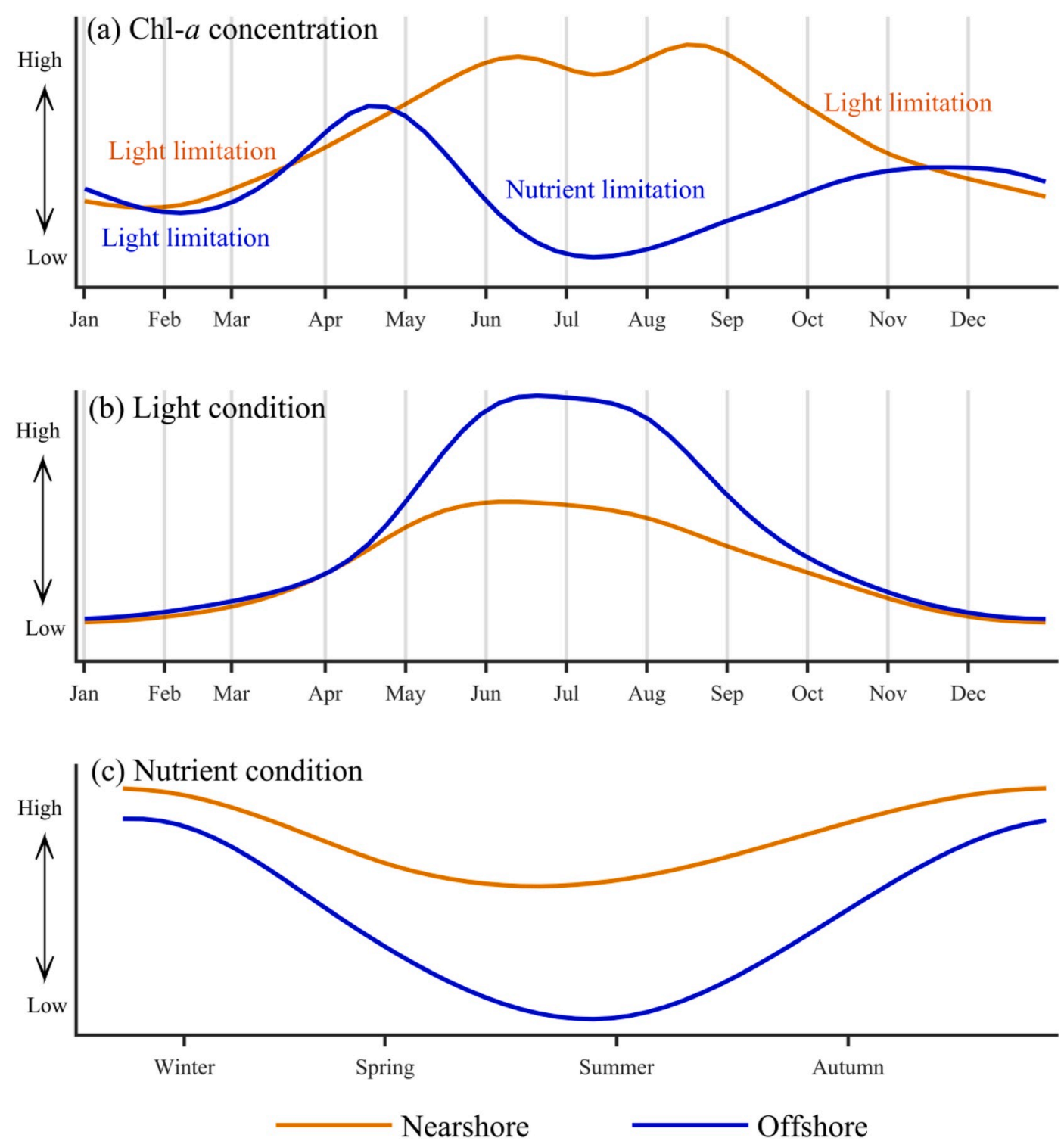

Fig. 8. Schematic annual cycles of sea surface Chl-a concentrations along with the corresponding light and nutrient conditions for the nearshore and offshore provinces. 

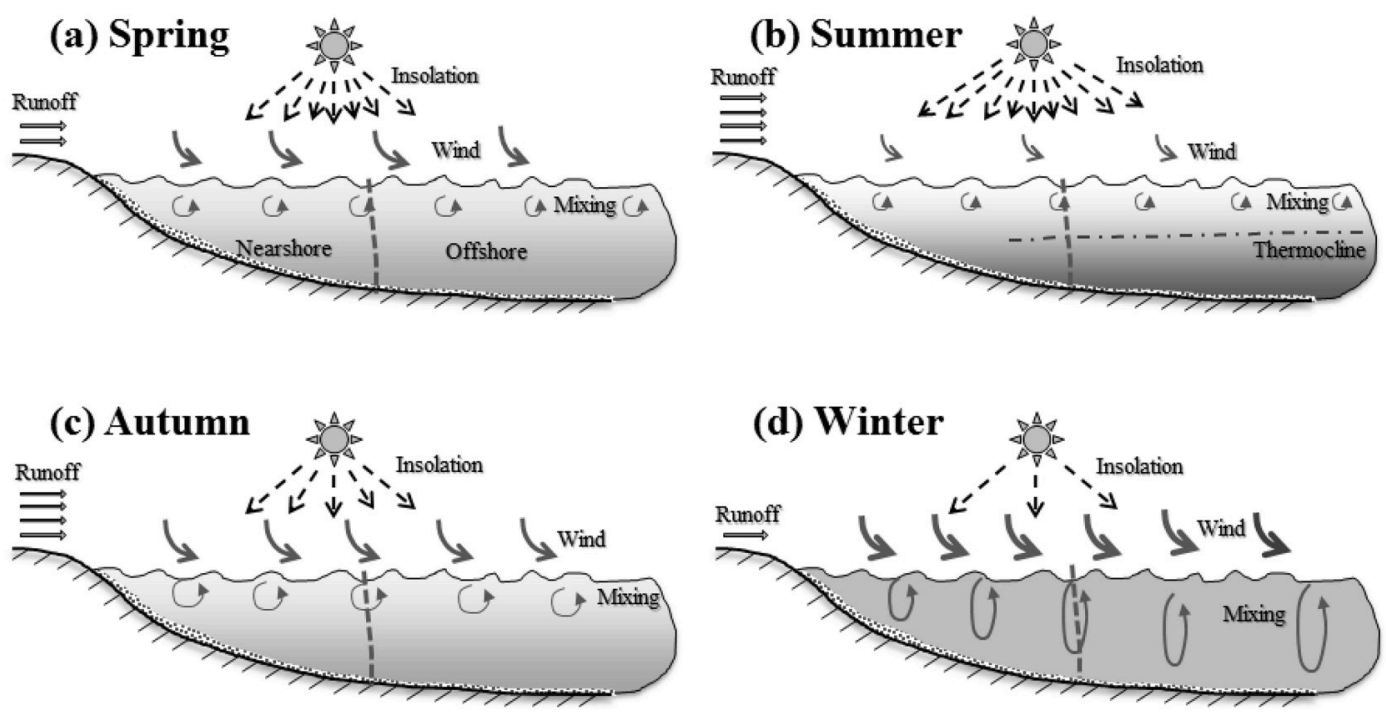

Fig. 9. Schematic diagram of the main environmental processes responsible for the seasonal cycles of Chl- $a$ in the BYS.

of the light. Despite high loadings of the terrestrial nutrients via increased runoff from the land into the coastal waters in this period (Chen et al., 2017; Qian et al., 2002; Tong et al., 2015), the nutrient supply from spring to summer decreased slightly, due to the high phytoplankton consumption associated with the diminished supply of bottom sediment re-suspension (Figs. 8 and 9). This concludes that the terrestrial-originated nutrients might be constrained in narrow bands around the coastal zone due to the high water stability during summer; meanwhile the land originated nutrient load was relatively lower than the total loads of nutrient consumed by the phytoplankton and diminished the supply from bottom sediments.

The Chl- $a$ reaches a maximum in summer when the light intensity reaches its highest level, despite the nutrient trough that occurs simultaneously (Figs. 8 and 9c). This phenomenon further confirmed that the nutrient limitation might be seldom take place in the nearshore waters. A transient Chl- $a$ dip appears in July, which is probably due to the coupled causality of lowest nutrient supply associated with highest zooplankton grazing pressure on the phytoplankton (Li et al., 2003; Sun et al., 2010; Zhang et al., 2005).

From summer to autumn, the Chl- $a$ is gradually decreasing with the deceasing light intensity and increasing nutrient supply (Figs. 7 and 8). The reduced light availability is attributed to the decreasing solar irradiance on the sea surface (Fig. 4e) and the increasing diffuse attenuation coefficient of light in the water column (Fig. $4 \mathrm{f}$ ). During this period, the increasing SSW leads to enhanced vertical mixing and strong bottom sediment re-suspension, thus increasing nutrient supply from the bottom sediment as well as increasing the light diffuse attenuation coefficient due to increasing TSM in the water column (Qian et al., 2002; Shang et al., 2016). Overall, the phytoplankton growth in the nearshore province is always controlled by the light availability in autumn.

In summary, light availability is probably a persistent limiting factor for phytoplankton growth in the nearshore province, while the nutrient availability appears almost sufficient for phytoplankton growth all yearround, except in July with a transient small dip in Chl-a.

\subsubsection{Offshore province}

As in the nearshore province, the phytoplankton growth in the offshore waters is also impacted by the limited availability of light in winter due to the low solar irradiance on the water surface coinciding with a higher diffuse attenuation coefficient of light in the water column due to the strong wind-induced sediment re-suspension (Figs. 8 and 9d).

When the wind weakens and light availability increases in spring (Fig. 4), the phytoplankton grows rapidly in the stabilizing water column that has abundant nutrients accumulated in wintertime and a prominent spring bloom occurs (Xuan et al., 2011; Zhou et al., 2013). In addition, the YSWC might bring some nutrients into the central Yellow Sea from the subsurface nutrient-rich water of the Kuroshio and/or from the Changjiang (Yangtze) River estuary (Liu et al., 2015a, 2015b). The spring bloom generally persists for a few weeks to a month until the nutrients are depleted and the zooplankton grazing terminates the phytoplankton (Fig. 8). The phytoplankton bloom disappears in summer as a consequence of the strong vertical stratification that occurs due to the high SST (Fig. 4a), weak SSW (Fig. 4b) and strong Yellow Sea Cold Water Mass (YSCWM) (Zhang et al., 2008). The strong sea surface stratification reduces the nutrient supply from the deeper layers to the upper euphotic layer and thus limits the phytoplankton growth in summer (Hyun and Kim, 2003; Naimie et al., 2001). Then, a secondary phytoplankton bloom occurs in autumn as the nutrient limitation is relaxed by surface cooling and vertical mixing (Naimie et al., 2001; Wang, 2003; Wang et al., 2003). From autumn to winter, the solar irradiance decreases and more importantly the vertical mixing gradually intensifies due to the increasing SSW, and diffuse attenuation coefficient of light enhances due to the re-suspended bottom sediment (Bian et al., 2013). Therefore, the light availability gradually reduces during this period (Fig. 8). Although plenty of nutrients accumulated in the surface water, the light limitation restricts phytoplankton growth in winter, resulting in the presence of a secondary trough of Chl- $a$.

In summary, in the offshore province, the first Chl- $a$ trough in summer from May to August is mainly induced by the nutrient limitation, whereas the second Chl- $a$ trough in winter from January to March is attributed to the light limitation.

\subsection{Other potential factors and their implications}

In natural waters, the phytoplankton uptake of $\mathrm{Si}, \mathrm{N}$, and $\mathrm{P}$ is usually in accordance with the Redfield ratio of 16:16:1 (Redfield, 1958, 1963); element concentrations that are too high or too low might cause the growth of phytoplankton to be restricted (Dortch and Whitledge, 1992). Justić et al. (1995) suggested absolute nutrient limitation thresholds of: $\mathrm{DIN}=1 \mu \mathrm{mol} \mathrm{L}{ }^{-1}$, DIP $=0.1 \mu \mathrm{mol} \mathrm{L}{ }^{-1}$ and DSi $=2 \mu \mathrm{mol} \mathrm{L}^{-1}$ for phytoplankton growth. In combination with the Redfield ratio and the absolute limitation criteria, a synoptic nutrient limitation status for the BYS could be drawn here. For the nearshore waters, almost no nutrient limitation was found throughout the year with all of the three nutrient elements above their absolute criteria, except for a probably slight P-limitation in summer (DIP $<0.06 \mu \mathrm{mol} \mathrm{L}^{-1}$ ). Despite ratios lower than 
16 for $\mathrm{N} / \mathrm{P}$ and $\mathrm{Si} / \mathrm{P}$ in the nearshore waters during winter, no N-limitation or Si-limitation would be suggested considering the high nutrient levels (DIN $>11 \mu \mathrm{mol} \mathrm{L}^{-1}$, DIP $>0.7 \mu \mathrm{mol} \mathrm{L}^{-1}$ and DSi $=11 \mu \mathrm{mol} \mathrm{L}^{-1}$ ) associated with the light-limitation of the phytoplankton growth during this period. For the offshore water, all of the three nutrient elements were below the absolute criteria in summer (DIN $<0.38 \mu \mathrm{mol} \mathrm{L}^{-1}$, DIP $<0.04 \mu \mathrm{mol} \mathrm{L}^{-1}$ and DSi $<1.48 \mu \mathrm{mol} \mathrm{L}^{-1}$ ), which suggested the presence of absolute nutrient limitation during this period. In spring, the low DIP (Fig. 6b) coincides with higher N/P and Si/P (both are larger than 16) (Fig. 6d and e) for the offshore waters, implying a probable P-limitation, which is consistent with the previous reports that the phosphate nutrient has become a primary limiting factor for phytoplankton growth in this area during the last two decades (Chen, 2008; Kim et al., 2009; Wang et al., 2003; Xin et al., 2019; Yang et al., 2018). For the offshore province, no N-limitation or Si-limitation was found during winter considering the higher nutrient levels associated with the light-limitation of the phytoplankton growth in this period (Fig. 8).

Compared with vertical mixing, the horizontal processes such as surface transport, mixing, and stirring also play non-negligible roles in regulating the dynamics of biological activities in the ocean surface (Aouni et al., 2019; Gruber et al., 2011; Haller and Beron-Vera, 2012; Rossi et al., 2009). These surface horizontal transport processes imposed positive or negative impact on the sea surface phytoplankton stock through redistributing the nutrient abundance and/or driving the phytoplankton movement laterally (Lacour et al., 2017; Rossi et al., 2008). To date, the relationship between the stretch of sea surface horizontal processes and biological production in the ocean is an open question. For example, according to earlier studies (Falkowski et al., 1991; McGillicuddy et al., 1998), surface and subsurface mesoscale processes can enhance biological production in the ocean, particularly in the low-nutrient environments where these surface processes increase the net upward flux of limiting nutrients (McGillicuddy et al., 2007; Oschlies and Garcon, 1998). However, the surface eddies suppress the biological activities in some high productive systems and as a consequence reducing the local nutrient content by horizontal transportation (Lacour et al., 2017). Concentrating on the Bohai Sea, several previous studies based on biological-physical models have elucidated that the horizontal advection can dramatically alter the horizontal distribution of Chl- $a$ (Wei et al., 2004; Zhao and Wei, 2005). Although the horizontal advection could affect the relative magnitude of Chl- $a$ bloom, the shape of periodic Chl- $a$ seasonality was clearly not changed by the horizontal processes (Wei et al., 2004; Zhao and Wei, 2005). As a shallow marginal sea, the surface physical structures of the BYS are quite complex and are generally dominated by the tidal currents, wind-waves, river discharges, and some other dynamic factors (Huang et al., 2010; Yuan et al., 2005; Zhou et al., 2017). Therefore, it is probably not appropriate to quantify the intensity of surface mixing only from the geostrophic current velocity using the method introduced in Aouni et al. (2019). For example, Waugh and Abraham (2008) addresses only the variations in global sea surface stirring over open waters without considering the shallow coastal regions (depth $<1000 \mathrm{~m}$ ). In summary, for the complex and shallow BYS, the horizontal processes may play lower order roles for determining the sea surface Chl- $a$ concentration, compared with other physical factors such as vertical mixing and light condition. These horizontal processes probably impose limited effects on shaping the seasonal cycles of Chl- $a$, but could change the relative magnitude of Chl- $a$ sometimes.

In this study, we discussed only a physically mediated effect of SST on the vertical stratification that indirectly affects the phytoplankton growth by limiting the nutrient supply available in the upper layer of ocean. However, the SST also could impose a direct effect on the phytoplankton and zooplankton metabolic rates (Lewandowska et al., 2014; Sommer and Lewandowska, 2011). However, Marañón et al. (2018) suggested that the direct effect of rising temperatures upon the phytoplankton metabolic rates would be circumscribed to ecosystems with high-nutrient availability. The nutrient supply explains most of the variability in the photosynthesis and respiration of phytoplankton, whereas temperature plays a much smaller role. Indirect effects of temperature upon resource supply are therefore likely to dominate the response of phytoplankton growth to the changes in SST (Marañon et al., 2018). Therefore, as a eutrophic region, we suggest that SST imposes much lower order direct effect than its indirect effect on Chl- $a$ seasonal cycle, which inadequately shape the Chl- $a$ seasonal climatology of the BYS.

The variations in Chl- $a$ concentration represent the changes in phytoplankton standing stock, reflecting the minor disequilibrium of phytoplankton division and loss rate (Behrenfeld and Boss, 2014). Therefore, the impact of phytoplankton loss that is mainly driven by the grazing pressure could impose some degree of effect on the Chl- $a$ variability. Some studies have reported that in the BYS, the grazing pressure can be much higher than the phytoplankton productivity in the coastal region during summer and might cause an unstable seasonal variation in the Chl- $a$ (Hao et al., 2019; Tang et al., 2003; Zhang and Wang, 2000). However, the loss rate impact on Chl- $a$ seasonal cycles is still unclear due to a lack of large-scale and time-continuous grazing rate studies. The Chl- $a$ tip in the nearshore pattern during summer (Fig. 3d), to some extent, might be related to the zooplankton grazing activities, which also need further exploration.

Atmospheric deposition could be another indispensable nutrient source for the BYS, thus imposing some degree of fertilizing impacts on the phytoplankton growth here (Shi et al., 2012; Tan and Shi, 2012). However, the atmospheric deposition fluxes mainly take place in spring and summer, and could mainly alter the magnitude and/or timing of the phytoplankton bloom, but probably not significantly shape the seasonal cycles of Chl-a (Joo-Eun et al., 2017; Tan and Wang, 2014; Tan et al., 2011).

\section{Concluding remarks}

In this study, an objective clustering analysis was performed on the new satellite Chl- $a$ data for the BYS, and two contrasting Chl- $a$ seasonal patterns were delineated between the nearshore and offshore regions. A unimodal pattern with a prominent long-lasting spring to autumn maxima and a winter minima generally dominates the nearshore area with isobaths $<50 \mathrm{~m}$. In the nearshore waters, the high level of Chl- $a$ from spring to autumn was mainly induced by weakened light constrain and sufficient nutrient accumulation, while the winter minima was attributed to the strong light limitation. In contrast, a bimodal pattern with a strong spring bloom and a weak autumn peak was generally observed over the offshore area with isobaths $>50 \mathrm{~m}$. In offshore waters, the spring bloom was induced by the increasing water column stability and decreasing light limitation, while the autumn bloom was attributed to the nutrient replenishment by vertical and horizontal convections. The summer Chl- $a$ trough in the offshore waters was caused by nutrient limitation, while the winter trough was attributed to the light limitation for phytoplankton growth. The new delineated Chl- $a$ seasonal patterns confirms that the winter bloom of satellite derived Chl- $a$ being reported in previous studies might be a spurious feature and was mainly resulted from the significant overestimation of remotely sensed Chl- $a$ products during winter. The results of this study might be of interest to detect and understand the interannual variability in phytoplankton biomass and the changes in phytoplankton phenology in the coming studies.

The present study provided an overview of the spatiallyheterogeneous Chl- $a$ annual cycles and their potential divers in the BYS, highlighting the main features of the BYS as well as its complexity. However, most mechanisms have been presented here were rely on qualitative analysis, further statistical analyses are needed to address these relationships quantitatively. In addition, it should be noted that the satellite remote sensing data only retrieved the sea surface variables, more comprehensive understanding about the dynamics of Chl-a need to integrate the satellite observations with the field surveys and the biophysical model simulations for further exploring the three-dimensional 
dynamics of Chl- $a$ in the water column. Furthermore, the changes of phytoplankton community (composition and structure) might also influence the variability of phytoplankton biomass which was not considered here and need further addressed in future.

\section{Declaration of competing interest}

There are no conflicts of interest.

\section{Acknowledgements}

This work was supported by the National Natural Science Foundation of China [grant numbers 41706134, 41876107]; the Open Fund of CAS Key Laboratory of Marine Ecology and Environmental Sciences, Institute of Oceanology, Chinese Academy of Sciences [KLMEES202005]; the NSFC-Shandong joint fund project [grant number U1706219]; the Key Research Program of Center for Ocean Mega-Science, Chinese Academy of Sciences [No.COMS2019J02]; the Key Research Program of Frontier Science of Chinese Academy of Sciences [No. ZDBS-LY-7010].

\section{References}

Alvera-Azcárate, A., Barth, A., Beckers, J.M., Weisberg, R.H., 2007. Multivariate reconstruction of missing data in sea surface temperature, chlorophyll, and wind satellite fields. J. Geophys. Res. 112. C03008.

Alvera-Azcárate, A., Barth, A., Rixen, M., Beckers, J.M., 2005. Reconstruction of incomplete oceanographic data sets using empirical orthogonal functions: application to the Adriatic Sea surface temperature. Ocean Model. 9, 325-346.

Aouni, A.E., Daoudi, K., Yahia, H., Minaoui, K., Benazzouz, A., 2019. Surface mixing and biological activity in the North-West African upwelling. Chaos: Interdiscipl. J. Nonlinear Sci. 29, 011104.

Atlas, R., Hoffman, R.N., Ardizzone, J., Leidner, S.M., Jusem, J.C., Smith, D.K., Gombos, D., 2011. A cross-calibrated, multiplatform ocean surface wind velocity product for meteorological and oceanographic applications. Bull. Am. Meteorol. Soc. 92, 157-174.

Atlas, R., Hoffman, R.N., Bloom, S.C., Jusem, J.C., Ardizzone, J., 1996. A multiyear global surface wind velocity dataset using SSM/I wind observations. Bull. Am. Meteorol. Soc. 77, 869-882.

Barnes, R.S.K., Hughes, R.N., 1999. An Introduction to Marine Ecology. John Wiley \& Sons.

Beckers, J.-M., Barth, A., Alvera, A., 2006. DINEOF Reconstruction of Clouded Images Including Error Maps. Application to the Sea-Surface Temperature Around Corsican Island. European Geosciences Union.

Beckers, J.M., Rixen, M., 2003. EOF calculations and data filling from incomplete oceanographic datasets. J. Atmos. Ocean. Technol. 20, 1839-1856.

Behrenfeld, M.J., Boss, E.S., 2014. Resurrecting the ecological underpinnings of ocean plankton blooms. Ann. Rev. Mar. Sci. 6, 167-194.

Bian, C., Jiang, W., Quan, Q., Wang, T., Greatbatch, R.J., Li, W., 2013. Distributions of suspended sediment concentration in the Yellow Sea and the East China Sea based on field surveys during the four seasons of 2011. J. Mar. Syst. 121-122, 24-35.

Carstensen, J., Henriksen, P., Heiskanen, A.S., 2007. Summer algal blooms in shallow estuaries: definition, mechanisms, and link to eutrophication. Limnol. Oceanogr. 52, 370-384.

Chassignet, E.P., Hurlburt, H.E., Smedstad, O.M., Halliwell, G.R., Hogan, P.J., Wallcraft, A.J., Baraille, R., Bleck, R., 2007. The HYCOM (HYbrid Coordinate Ocean Model) data assimilative system. J. Mar. Syst. 65, 60-83.

Chen, C.-T.A., 2008. Distributions of nutrients in the East China sea and the south China sea connection. J. Oceanogr. 64, 737-751.

Chen, C.-T.A., 2009. Chemical and physical fronts in the Bohai, yellow and East China seas. J. Mar. Syst. 78, 394-410.

Chen, C., Mao, Z., Tang, F., Han, G., Jiang, Y., 2017. Declining riverine sediment input impact on spring phytoplankton bloom off the Yangtze River Estuary from 17-year satellite observation. Continent. Shelf Res. 135, 86-91.

Dortch, Q., Whitledge, T.E., 1992. Does nitrogen or silicon limit phytoplankton production in the Mississippi River plume and nearby regions? Continent. Shelf Res. 12, 1293-1309.

Falkowski, P.G., Barber, R.T., Smetacek, V., 1998. Biogeochemical controls and feedbacks on ocean primary production. Science 281, 200-206.

Falkowski, P.G., Ziemann, D., Kolber, Z., Bienfang, P.K., 1991. Role of eddy pumping in enhancing primary production in the ocean. Nature 352, 55.

Foukal, N.P., Thomas, A.C., 2014. Biogeography and phenology of satellite-measured phytoplankton seasonality in the California current. Deep-Sea Res Pt I 92, 11-25.

Friedland, K.D., Mouw, C.B., Asch, R.G., Ferreira, A.S.A., Henson, S., Hyde, K.J.W., Morse, R.E., Thomas, A.C., Brady, D.C., 2018. Phenology and time series trends of the dominant seasonal phytoplankton bloom across global scales. Global Ecol. Biogeogr. 27, 551-569.

Frouin, R., 2003. The SeaWiFS PAR product. In: Hooker, S.B., Firestone, E.R. (Eds.), Algorithm Updates for the Fourth SeaWiFS Data Reprocessing, pp. 45-50.
Fu, M., Wang, Z., Li, Y., Li, R., Sun, P., Wei, X., Lin, X., Guo, J., 2009. Phytoplankton biomass size structure and its regulation in the Southern Yellow Sea (China): seasonal variability. Continent. Shelf Res. 29, 2178-2194.

Fu, Y., Xu, S., Liu, J., 2016. Temporal-spatial variations and developing trends of chlorophyll-a in the Bohai Sea, China. Estuarine. Coast Shelf Sci. 173, 49-56.

Gabriel, R., Alan, L., Elodie, M., Gregory, B., David, A., Olivier, M., 2013. Dynamic biogeochemical provinces in the global ocean. Global Biogeochem. Cycles 27, 1046-1058.

Garcia, V.M.T., Garcia, C.A.E., Mata, M.M., Pollery, R.C., Piola, A.R., Signorini, S.R. McClain, C.R., Iglesias-Rodriguez, M.D., 2008. Environmental factors controlling the phytoplankton blooms at the Patagonia shelf-break in spring. Deep Sea Res. Oceanogr. Res. Pap. 55, 1150-1166.

Gong, G.C., Wen, Y.H., Wang, B.W., Liu, G.J., 2003. Seasonal variation of chlorophyll a concentration, primary production and environmental conditions in the subtropical East China Sea. Deep-Sea Res Pt Ii 50, 1219-1236.

González Taboada, F., Anadón, R., 2014. Seasonality of North Atlantic phytoplankton from space: impact of environmental forcing on a changing phenology (1998-2012). Global Change Biol. 20, 698-712.

Gordon, L.I., Jennings Jr., J.C., Ross, A.A., Krest, J.M., 1993. A suggested protocol for continuous flow automated analysis of seawater nutrients (phosphate, nitrate, nitrite and silicic acid) in the WOCE Hydrographic Program and the Joint Global Ocean Fluxes Study. WOCE Operations Manual, Part 3, 1-52.

Gruber, N., Lachkar, Z., Frenzel, H., Marchesiello, P., Münnich, M., McWilliams, J.C., Nagai, T., Plattner, G.-K., 2011. Eddy-induced reduction of biological production in eastern boundary upwelling systems. Nat. Geosci. 4, 787-792.

Haller, G., Beron-Vera, F.J., 2012. Geodesic theory of transport barriers in twodimensional flows. Phys. Nonlinear Phenom. 241, 1680-1702.

Halliwell, G.R., 2004. Evaluation of vertical coordinate and vertical mixing algorithms in the HYbrid-Coordinate Ocean Model (HYCOM). Ocean Model. 7, 285-322.

Hao, Q., Chai, F., Xiu, P., Bai, Y., Chen, J.F., Liu, C.G., Le, F.F., Zhou, F., 2019. Spatial and temporal variation in chlorophyll a concentration in the Eastern China Seas based on a locally modified satellite dataset. Estuar. Coast Shelf Sci. 220, 220-231.

Hu, C.M., Li, D.Q., Chen, C.S., Ge, J.Z., Muller-Karger, F.E., Liu, J.P., Yu, F., He, M.X., 2010. On the recurrent ulva prolifera blooms in the Yellow Sea and East China sea. J. Geophys. Res. Oceans 115. C05017.

Huang, D., Zhang, T., Zhou, F., 2010. Sea-surface temperature fronts in the Yellow and East China Seas from TRMM microwave imager data. Deep Sea Res. Part II Top. Stud. Oceanogr. 57, 1017-1024.

Hyun, J.-H., Kim, K.-H., 2003. Bacterial abundance and production during the unique spring phytoplankton bloom in the central Yellow Sea. Mar. Ecol. Prog. Ser. 252, 77-88.

Joo-Eun, Y., Kitae, K., M, M.A., Ki-Tae, P., Hyun-Cheol, K., Kyu-Cheul, Y., Ho-Il, Y., Jin, Y.E., Jinyoung, J., Jae-Hyun, L., Ju-Hyoung, K., Jiyoung, L., Tae-Jun, C., JaeMin, S., Il-Nam, K., 2017. Spatial and temporal variabilities of spring Asian dust events and their impacts on chlorophyll-a concentrations in the western North Pacific Ocean. Geophys. Res. Lett. 44, 1474-1482.

Justić, D., Rabalais, N.N., Turner, R.E., Dortch, Q., 1995. Changes in nutrient structure of river-dominated coastal waters: stoichiometric nutrient balance and its consequences. Estuar. Coast Shelf Sci. 40, 339-356.

Kanungo, T., Mount, D.M., Netanyahu, N.S., Piatko, C.D., Silverman, R., Wu, A.Y., 2002. An efficient k-means clustering algorithm: analysis and implementation. IEEE Trans. Pattern Anal. Mach. Intell. 24, 881-892.

Kim, D., Choi, S.H., Kim, K.H., Shim, J., Yoo, S., Kim, C.H., 2009. Spatial and temporal variations in nutrient and chlorophyll-a concentrations in the northern East China Sea surrounding Cheju Island. Continent. Shelf Res. 29, 1426-1436.

Kim, H.C., Son, S., Kim, Y.H., Khim, J.S., Nam, J., Chang, W.K., Lee, J.H., Lee, C.H., Ryu, J., 2017. Remote sensing and water quality indicators in the Korean West coast: spatio-temporal structures of MODIS-derived chlorophyll-a and total suspended solids. Mar. Pollut. Bull. 121, 425-434.

Kirk, J.T., 1994. Light and Photosynthesis in Aquatic Ecosystems. Cambridge university press.

Knap, A., Michaels, A., Close, A., Ducklow, H., Dickson, A., 1996. Protocols for the Joint Global Ocean Flux Study (JGOFS) Core Measurements. Reprint of the IOC Manuals and Guides No. 29. UNESCO 1994. JGOFS Report Nr. 19.

Krug, L.A., Platt, T., Sathyendranath, S., Barbosa, A.B., 2017. Ocean surface partitioning strategies using ocean colour remote Sensing: a review. Prog. Oceanogr. 155, 41-53.

Lacour, L., Ardyna, M., Stec, K.F., Claustre, H., Prieur, L., Poteau, A., D’Alcala, M.R., Iudicone, D., 2017. Unexpected winter phytoplankton blooms in the North Atlantic subpolar gyre. Nat. Geosci. 10, 836-839.

Leng, X., 2016. The Distribution of Nutrients and Phytoplankton Biomass in North China Sea (In Chinese with English Abstract). Tianjin University of Science\&Technology, Tianjin.

Lewandowska, A.M., Boyce, D.G., Hofmann, M., Matthiessen, B., Sommer, U., Worm, B., 2014. Effects of sea surface warming on marine plankton. Ecol. Lett. 17, 614-623.

Li, C., Wang, R., Sun, S., 2003. Grazing impact of copepods on phytoplankton in the Bohai Sea. Estuar. Coast Shelf Sci. 58, 487-498.

Li, Y., Hu, Y., Chen, s., 2013a. Distribution and influence factors of nutrients in the North Yellow Sea in summer and autumn (in Chinese with English abstract). China Environ. Sci. 33, 1060-1067.

Li, Y.H., Ye, X., Wang, A.J., Li, H.D., Chen, J., Qiao, L., 2013b. Impact of typhoon morakot on chlorophyll a distribution on the inner shelf of the East China sea. Mar. Ecol. Prog. Ser. 483, 19-29.

Lie, H.-J., Cho, C.-H., Lee, S., 2009. Tongue-shaped frontal structure and warm water intrusion in the southern Yellow Sea in winter. J. Geophys. Res.: Oceans 114. C01003. 
Lin, X.P., Xie, S.P., Chen, X.P., Xu, L.L., 2006. A well-mixed warm water column in the central Bohai Sea in summer: effects of tidal and surface wave mixing. J. Geophys. Res. Oceans 111. C11017.

Liu, D., Wang, Y., 2013. Trends of satellite derived chlorophyll-a (1997-2011) in the Bohai and Yellow Seas, China: effects of bathymetry on seasonal and inter-annual patterns. Prog. Oceanogr. 116, 154-166.

Liu, D.Y., Keesing, J.K., He, P.M., Wang, Z.L., Shi, Y.J., Wang, Y.J., 2013. The world's largest macroalgal bloom in the Yellow Sea, China: formation and implications. Estuar. Coast Shelf Sci. 129, 2-10.

Liu, X., Chiang, K.-P., Liu, S.-M., Wei, H., Zhao, Y., Huang, B.-Q., 2015a. Influence of the Yellow Sea warm current on phytoplankton community in the central Yellow Sea. Deep Sea Res. Oceanogr. Res. Pap. 106, 17-29.

Liu, X., Huang, B., Huang, Q., Wang, L., Ni, X., Tang, Q., Sun, S., Wei, H., Liu, S., Li, C., Sun, J., 2015b. Seasonal phytoplankton response to physical processes in the southern Yellow Sea. J. Sea Res. 95, 45-55.

Lorenzen, C.J., 1967. Determination of chlorophyll and pheopigments: spectrophotometric equations. Limnol. Oceanogr. 12, 343-346.

Manly, B.F., Alberto, J.A.N., 2016. Multivariate Statistical Methods: a Primer. CRC Press.

Marañón, E., Lorenzo, M.P., Cermeño, P., Mouriño-Carballido, B., 2018. Nutrient limitation suppresses the temperature dependence of phytoplankton metabolic rates. ISME J. 12, 1836-1845.

Mask, A.C., O'Brien, J.J., Preller, R., 1998. Wind-driven effects on the Yellow Sea warm current. J. Geophys. Res. Oceans 103, 30713-30729.

McClain, C.R., 2009. A decade of satellite ocean color observations*. Ann. Rev. Mar. Sci. $1,19-42$.

McGillicuddy, D.J., Anderson, L.A., Bates, N.R., Bibby, T., Buesseler, K.O., Carlson, C.A., Davis, C.S., Ewart, C., Falkowski, P.G., Goldthwait, S.A., 2007. Eddy/wind interactions stimulate extraordinary mid-ocean plankton blooms. Science 316, 1021-1026.

McGillicuddy Jr., D.J., Robinson, A., Siegel, D., Jannasch, H., Johnson, R., Dickey, T., McNeil, J., Michaels, A., Knap, A., 1998. Influence of mesoscale eddies on new production in the Sargasso Sea. Nature 394, 263.

McGinty, N., Guðmundsson, K., Ágústsdóttir, K., Marteinsdóttir, G., 2016. Environmental and climactic effects of chlorophyll-a variability around Iceland using reconstructed satellite data fields. J. Mar. Syst. 163, 31-42.

Melin, F., Zibordi, G., Berthon, J.F., 2007. Assessment of satellite ocean color products at a coastal site. Rem. Sens. Environ. 110, 192-215.

Naimie, C., Ann Blain, C., R Lynch, D., 2001. Seasonal mean circulation in the Yellow Sea-a model-generated climatology. Continent. Shelf Res. 21, 667-695.

O'Reilly, J.E., Maritorena, S., Siegel, D., 2000. Ocean Color Chlorophyll a Algorithms for SeaWiFS, OC2, and OC4: Version 4, SeaWiFS Postlaunch Calibration and Validation Analyses, Part 3. NASA Goddard Space Flight Center, pp. 9-23.

Odermatt, D., Gitelson, A., Brando, V.E., Schaepman, M., 2012. Review of constituent retrieval in optically deep and complex waters from satellite imagery. Rem. Sens. Environ. 118, 116-126.

Oschlies, A., Garcon, V., 1998. Eddy-induced enhancement of primary production in a model of the North Atlantic Ocean. Nature 394, 266.

Park, K.-A., Lee, E.-Y., Chang, E., Hong, S., 2015. Spatial and temporal variability of sea surface temperature and warming trends in the Yellow Sea. J. Mar. Syst. 143, 24-38.

Pielou, E.C., 1984. The Interpretation of Ecological Data: a Primer on Classification and Ordination. John Wiley \& Sons.

Platt, T., Sathyendranath, S., 2008. Ecological indicators for the pelagic zone of the ocean from remote sensing. Rem. Sens. Environ. 112, 3426-3436.

Qian, W., Kang, H.S., Lee, D.K., 2002. Distribution of seasonal rainfall in the East Asian monsoon region. Theor. Appl. Climatol. 73, 151-168.

Redfield, A.C., 1958. The biological control of chemical factors in the environment. Am. Sci. 46, 205-221.

Redfield, A.C., 1963. The influence of organisms on the composition of seawater. Sea 2, 26-77.

Reynolds, R.W., Smith, T.M., 1994. Improved global sea-surface temperature analyses using Optimum interpolation. J. Clim. 7, 929-948.

Reynolds, R.W., Smith, T.M., Liu, C., Chelton, D.B., Casey, K.S., Schlax, M.G., 2007. Daily high-resolution-blended analyses for sea surface temperature. J. Clim. 20, 5473-5496.

Richards, F.A., Thompson, T.G., 1952. The estimation and characterization of plankton populations by pigment analyses .2. A spectrophotometric method for the estimation of plankton pigments. J. Mar. Res. 11, 156-172.

Rossi, V., López, C., Hernández-García, E., Sudre, J., Garçon, V., Morel, Y., 2009. Surface mixing and biological activity in the four eastern boundary upwelling systems. Nonlinear Process Geophys. 16, 557-568.

Rossi, V., López, C., Sudre, J., Hernández-García, E., Garçon, V., 2008. Comparative study of mixing and biological activity of the Benguela and Canary upwelling systems. Geophys. Res. Lett. 35, L11602.

Rousseeuw, P.J., 1987. Silhouettes - a graphical aid to the interpretation and validation of cluster-analysis. J. Comput. Appl. Math. 20, 53-65.

Ryther, J.H., Yentsch, C.S., 1957. The estimation of phytoplankton production in the ocean from chlorophyll and light data. Limnol. Oceanogr. 2, 281-286.

Sapiano, M.R.P., Brown, C.W., Schollaert Uz, S., Vargas, M., 2012. Establishing a global climatology of marine phytoplankton phenological characteristics. J. Geophys. Res.: Oceans 117. C08026.

Shalin, S., Samuelsen, A., Korosov, A., Menon, N., Backeberg, B.C., Pettersson, L.H., 2018. Delineation of marine ecosystem zones in the northern Arabian Sea during winter. Biogeosciences 15, 1395-1414.

Shang, S., Lee, Z., Shi, L., Lin, G., Wei, G., Li, X., 2016. Changes in water clarity of the Bohai Sea: observations from MODIS. Rem. Sens. Environ. 186, 22-31.
Shi, J.-H., Gao, H.-W., Zhang, J., Tan, S.-C., Ren, J.-L., Liu, C.-G., Liu, Y., Yao, X., 2012. Examination of causative link between a spring bloom and dry/wet deposition of Asian dust in the Yellow Sea, China. J. Geophys. Res.: Atmosphere 117. D17304.

Siswanto, E., Tang, J., Yamaguchi, H., Ahn, Y.-H., Ishizaka, J., Yoo, S., Kim, S.-W., Kiyomoto, Y., Yamada, K., Chiang, C., Kawamura, H., 2011. Empirical ocean-color algorithms to retrieve chlorophyll-a , total suspended matter, and colored dissolved organic matter absorption coefficient in the Yellow and East China Seas. J. Oceanogr. $67,627-650$.

Sommer, U., Lewandowska, A., 2011. Climate change and the phytoplankton spring bloom: warming and overwintering zooplankton have similar effects on phytoplankton. Global Change Biol. 17, 154-162.

Son, S., Kim, Y.H., Kwon, J.-I., Kim, H.-C., Park, K.-S., 2014. Characterization of spatial and temporal variation of suspended sediments in the Yellow and East China Seas using satellite ocean color data. GIScience Remote Sens. 51, 212-226.

Son, S., Wang, M., 2015. Diffuse attenuation coefficient of the photosynthetically available radiation Kd (PAR) for global open ocean and coastal waters. Rem. Sens. Environ. 159, 250-258.

Son, S.H., Platt, T., Bouman, H., Lee, D.K., Sathyendranath, S., 2006. Satellite observation of chlorophyll and nutrients increase induced by Typhoon Megi in the Japan/East Sea. Geophys. Res. Lett. 33. L05607.

Song, N.-q., Wang, N., Lu, Y., Zhang, J.-r., 2016. Temporal and spatial characteristics of harmful algal blooms in the Bohai Sea during 1952-2014. Continent. Shelf Res. 122, $77-84$.

Su, J., 1998. Circulation dynamics of the China Seas north of 18 N. Sea 11, 483-505.

Sun, S., Huo, Y., Yang, B., 2010. Zooplankton functional groups on the continental shelf of the yellow sea. Deep Sea Res. Part II Top. Stud. Oceanogr. 57, 1006-1016.

Tan, S.-C., Wang, H., 2014. The transport and deposition of dust and its impact on phytoplankton growth in the Yellow Sea. Atmos. Environ. 99, 491-499.

Tan, S.C., Shi, G.Y., 2012. The relationship between satellite-derived primary production and vertical mixing and atmospheric inputs in the Yellow Sea cold water mass. Continent. Shelf Res. 48, 138-145.

Tan, S.C., Shi, G.Y., Shi, J.H., Gao, H.W., Yao, X.H., 2011. Correlation of Asian dust with chlorophyll and primary productivity in the coastal seas of China during the period from 1998 to 2008. J. Geophys. Res. Biogeo. 116. G02029.

Tang, Q., Jin, X., Wang, J., Zhuang, Z., Cui, Y., Meng, T., 2003. Decadal-scale variations of ecosystem productivity and control mechanisms in the Bohai Sea. Fish. Oceanogr. $12,223-233$.

Tong, Y., Zhao, Y., Zhen, G., Chi, J., Liu, X., Lu, Y., Wang, X., Yao, R., Chen, J., Zhang, W., 2015. Nutrient loads flowing into coastal waters from the main rivers of China (2006-2012). Sci. Rep. 5, 16678.

Wang, B., 2003. Nutrient distributions and their limitation on phytoplankton in the Yellow Sea and the East China Sea (in Chinese with English abstract). Chin. J. Appl. Ecol. 14, 1122-1126.

Wang, B., Wang, X., Zhan, R., 2003. Nutrient conditions in the Yellow Sea and the East China sea. Estuar. Coast Shelf Sci. 58, 127-136.

Wang, Y., Liu, D., 2014. Reconstruction of satellite chlorophyll-a data using a modified DINEOF method: a case study in the Bohai and Yellow seas, China. Int. J. Rem. Sens. 35, 204-217.

Wang, Y., Liu, D., Dong, Z., Di, B., Shen, X., 2012a. Temporal and spatial distributions of nutrients under the influence of human activities in Sishili Bay, northern Yellow Sea of China. Mar. Pollut. Bull. 64, 2708-2719.

Wang, Y., Wu, D., Lin, X., 2012b. The preliminary study of the high chlorophyll in the central Bohai Sea in summer. Acta Oceanol. Sin. 31, 66-72.

Wang, Y.Q., Liu, D.Y., Tang, D.L., 2017. Application of a generalized additive model (GAM) for estimating chlorophyll-a concentration from MODIS data in the Bohai and Yellow Seas, China. Int. J. Rem. Sens. 38, 639-661.

Wang, Y.Q., Liu, D.Y., Wang, Y.J., Gao, Z.Q., Keesing, J.K., 2019. Evaluation of standard and regional satellite chlorophyll-a algorithms for moderate-resolution imaging spectroradiometer (MODIS) in the Bohai and Yellow Seas, China: a comparison of chlorophyll-a magnitude and seasonality. Int. J. Rem. Sens. 40, 4980-4995.

Waugh, D.W., Abraham, E.R., 2008. Stirring in the global surface ocean. Geophys. Res. Lett. 35.

Wei, H., Shi, J., Lu, Y., Peng, Y., 2010a. Interannual and long-term hydrographic changes in the Yellow Sea during 1977-1998. Deep Sea Res. Part II Top. Stud. Oceanogr. 57, 1025-1034.

Wei, H., Sun, J., Moll, A., Zhao, L., 2004. Phytoplankton dynamics in the Bohai Sea observations and modelling. J. Mar. Syst. 44, 233-251.

Wei, J., Lee, Z., 2013. Model of the attenuation coefficient of daily photosynthetically available radiation in the upper ocean. Methods Oceang. 8, 56-74.

Wei, Q.-S., Yu, Z.-G., Wang, B.-D., Fu, M.-Z., Xia, C.-S., Liu, L., Ge, R.-F., Wang, H.-W., Zhan, R., 2016. Coupling of the spatial-temporal distributions of nutrients and physical conditions in the southern Yellow Sea. J. Mar. Syst. 156, 30-45.

Wei, Q.S., Fu, M.Z., Ge, R.F., Zang, J.Y., 2010b. Hemicohydrographic characteristics and the seasonal variations of nutrients at 35 degrees $\mathrm{N}$ transect in the cold water mass of the Southern Yellow Sea (in Chinese with English abstract). Environ. Sci. J. Integr. Environ. Res. 31, 2603-2074.

Wu, R.H., Lin, J.M., Li, B., 2016. Spatial and temporal variability of sea surface temperature in eastern marginal seas of China. Adv. Meterol. 2016, 1-9.

Xin, M., Wang, B., Xie, L., Sun, X., Wei, Q., Liang, S., Chen, K., 2019. Long-term changes in nutrient regimes and their ecological effects in the Bohai Sea, China. Mar. Pollut. Bull. 146, 562-573.

Xuan, J.-L., Zhou, F., Huang, D.-J., Wei, H., Liu, C.-G., Xing, C.-X., 2011. Physical processes and their role on the spatial and temporal variability of the spring phytoplankton bloom in the central Yellow Sea. Acta Ecol. Sin. 31, 61-70.

Yamaguchi, H., Ishizaka, J., Siswanto, E., Baek Son, Y., Yoo, S., Kiyomoto, Y., 2013. Seasonal and spring interannual variations in satellite-observed chlorophyll-a in the 
Yellow and East China Seas: new datasets with reduced interference from high concentration of resuspended sediment. Continent. Shelf Res. 59, 1-9.

Yamaguchi, H., Kim, H.-C., Son, Y.B., Kim, S.W., Okamura, K., Kiyomoto, Y., Ishizaka, J., 2012. Seasonal and summer interannual variations of SeaWiFS chlorophyll a in the Yellow Sea and East China sea. Prog. Oceanogr. 105, 22-29.

Yanagi, T., Takahashi, S., 1993. Seasonal variation of circulations in the East China sea and the Yellow Sea. J. Oceanogr. 49, 503-520.

Yang, F., Wei, Q., Chen, H., Yao, Q., 2018. Long-term variations and influence factors of nutrients in the western North Yellow Sea, China. Mar. Pollut. Bull. 135, 1026-1034.

Yoder, J.A., McClain, C.R., Feldman, G.C., Esaias, W.E., 1993. Annual cycles of phytoplankton chlorophyll concentrations in the global ocean: a satellite view. Global Biogeochem. Cycles 7, 181-193.

Yoder, J.A., Schollaert, S.E., O’Reilly, J.E., 2002. Climatological phytoplankton chlorophyll and sea surface temperature patterns in continental shelf and slope waters off the northeast US coast. Limnol. Oceanogr. 47, 672-682.

Yuan, D., Qiao, F., Su, J., 2005. Cross-shelf penetrating fronts off the southeast coast of China observed by MODIS. Geophys. Res. Lett. 32. L19603.

Zhang, F., Li, C.L., Sun, S., Wu, Y.L., Ren, J.P., 2009a. Distribution patterns of chlorophyll a in spring and autumn in association with hydrological features in the southern Yellow Sea and northern East China Sea. Chin. J. Oceanol. Limnol. 27, 784-792.

Zhang, H., Qiu, Z., Sun, D., Wang, S., He, Y., 2017. Seasonal and interannual variability of satellite-derived chlorophyll-a (2000-2012) in the Bohai Sea, China. Rem. Sens. 9, 582.

Zhang, H., Shi, X.Y., Zhang, C.S., Wang, L.S., 2009b. Distribution features of nutrients structure and nutrient limitation in the north of Yellow Sea (in Chinese with English abstract). Peroid. Ocean Univ. China 39, 773-780.
Zhang, L.Y., Sun, J., Liu, D.Y., Yu, Z.S., 2005. Studies on growth rate and grazing mortality rate by microzooplankton of size-fractionated phytoplankton in spring and summer in the Jiaozhou Bay, China. Acta Oceanol. Sin. 24, 85-101.

Zhang, M., Tang, J., Dong, Q., Song, Q., Ding, J., 2010. Retrieval of total suspended matter concentration in the Yellow and East China Seas from MODIS imagery. Rem. Sens. Environ. 114, 392-403.

Zhang, S.W., Wang, Q.Y., Lü, Y., Cui, H., Yuan, Y.L., 2008. Observation of the seasonal evolution of the Yellow Sea cold water mass in 1996-1998. Continent. Shelf Res. 28, 442-457.

Zhang, W., Wang, R., 2000. Summertime ciliate and copepod nauplii distributions and micro-zooplankton herbivorous activity in the laizhou bay, Bohai Sea, China. Estuarine. Coast Shelf Sci. 51, 103-114.

Zhao, L., Wei, H., 2005. The influence of physical factors on the variation of phytoplankton and nutrients in the Bohai Sea. J. Oceanogr. 61, 335-342.

Zhao, Y., He, R., 2012. Cloud-free sea surface temperature and colour reconstruction for the Gulf of Mexico: 2003-2009. Rem. Sens. Lett. 3, 697-706.

Zheng, C.W., Zhang, R., Shi, W.L., Li, X., Chen, X., 2017. Trends in significant wave height and surface wind speed in the China Seas between 1988 and 2011. J. Ocean Univ. China 16, 717-726.

Zheng, G.M., Tang, D., 2007. Offshore and nearshore chlorophyll increases induced by typhoon winds and subsequent terrestrial rainwater runoff. Mar. Ecol. Prog. Ser. 333, 61-74.

Zhou, F., Xuan, J., Huang, D., Liu, C., Sun, J., 2013. The timing and the magnitude of spring phytoplankton blooms and their relationship with physical forcing in the central Yellow Sea in 2009. Deep Sea Res. Part II Top. Stud. Oceanogr. 97, 4-15.

Zhou, Z., Bian, C.W., Wang, C.H., Jiang, W.S., Bi, R., 2017. Quantitative assessment on multiple timescale features and dynamics of sea surface suspended sediment concentration using remote sensing data. J. Geophys. Res. Oceans 122, 8739-8752. 